OPEN ACCESS

Edited by:

Cliff Ross,

University of North Florida

United States

Reviewed by:

Ewelina Rubin,

University of Miami, United States

Susann Rossbach,

Red Sea Development Company,

Saudi Arabia

*Correspondence:

Yuen K. Ip

dbsipyk@nus.edu.sg

${ }^{t}$ These authors have contributed equally to this work

Specialty section:

This article was submitted to Coral Reef Research,

a section of the journal

Frontiers in Marine Science

Received: 10 November 2020

Accepted: 13 January 2021

Published: 03 February 2021

Citation:

Ip YK and Chew SF (2021)

Light-Dependent Phenomena and Related Molecular Mechanisms

in Giant Clam-Dinoflagellate

Associations: A Review.

Front. Mar. Sci. 8:627722

doi: 10.3389/fmars.2021.627722

\section{Light-Dependent Phenomena and Related Molecular Mechanisms in Giant Clam-Dinoflagellate Associations: A Review}

\author{
Yuen K. Ip ${ }^{1 * t}$ and Shit F. Chew ${ }^{2 t}$ \\ ${ }^{1}$ Department of Biological Sciences, National University of Singapore, Singapore, Singapore, ${ }^{2}$ Natural Sciences \\ and Science Education, National Institute of Education, Nanyang Technological University, Singapore, Singapore
}

Giant clams can grow to large sizes despite living in oligotrophic waters of the tropical Indo-Pacific as they maintain a mutualistic relationship with symbiotic dinoflagellates (zooxanthellae) and receive photosynthate from them. The phototrophic dinoflagellates live extracellularly inside a tubular system located mainly in the colorful outer mantle and have no access to the ambient seawater. Hence, the clam host needs to absorb exogenous inorganic carbon $\left(\mathrm{C}_{i}\right)$, nitrogen $(\mathrm{N})$ and phosphorus $(\mathrm{P})$, and supply them to the symbionts. As photosynthesizing symbionts need more nutrients in light than in the dark, the uptake rates of these exogenous nutrients by the host must increase during illumination, implying that the host's transporters involved need to be regulated by some kind of light-responsive mechanisms. Furthermore, the growth and development of the host can also be augmented by light, because of the photosynthate donated by the photosynthesizing symbionts. Consequently, giant clams display many light-dependent phenomena related to phototrophy, antioxidative defense, biomineralization, as well as absorption of exogenous $\mathrm{C}_{i}, \mathrm{~N}$, and $\mathrm{P}$. These phenomena may involve collaborations among enzymes and transporters in several organs of the host, whereby the gene and protein expression levels of these biocatalysts are up- or down-regulated during illumination. This review aims to examine the molecular mechanisms of light-dependent physiological phenomena that occur in intact giant clam-dinoflagellate associations, and to highlight the differences between giant clams and scleractinian corals in those regards. As the population of giant clams in nature are dwindling due to climate change and anthropogenic activities, a good understanding of their light-dependent processes may generate new ideas to improve their growth and survival under rapidly changing environmental conditions.

Keywords: coral reefs, light-enhanced calcification, photosynthesis, symbiosis, zooxanthellae

\section{INTRODUCTION}

Giant clams (Phylum: Mollusca, Class: Bivalvia, Order: Veneroida, Family: Cardiidae, and Subfamily: Tridacninae) are among the world's largest living marine bivalves found exclusively in the tropical Indo-Pacific, mainly as inhabitants of coral reefs (Goh and Todd, 2010; Neo et al., 2017). Currently, there are 12 described giant clam species classified under two genera, 
Hippopus and Tridacna (Neo et al., 2017). Giant clams are important ecosystem engineers whose large $\mathrm{CaCO}_{3}$ shells contribute to the formation and maintenance of extensive reef habitats (Neo et al., 2015). Moreover, they filter large volumes of seawater, contributing to the effective recycling of nutrients and organic matter that maintain the productivity of tropical reefs (Klumpp and Griffiths, 1994; de Goeij et al., 2013).

Tropical waters have water temperatures of $>20^{\circ} \mathrm{C}$, and are crystal-clear because of the absence of plankton and suspended particles. In comparison, temperate waters are murky and blue-green in color because of the high plankton content in waters close to the surface. Phototrophic phytoplankton can fix inorganic carbon $\left(\mathrm{C}_{i}\right)$ into organic molecules, and they can act as basic nutritional sources for heterotrophic organisms. In temperate regions, the cold surface waters can sink, causing overturn, and bring nutrients from the bottom to sunlit regions in support of phytoplankton growth. By contrast, tropical waters have a high temperature at the surface and therefore lack overturn. As a result, they are poor in nutrients and are often regarded as 'deserts of the sea.' Yet, shallow tropical waters are home to coral reefs that comprise great diversity and high density of life forms.

To overcome the scarcity of organic nutrients, many reef animals live in symbiosis with certain species of phytoplankton (dinoflagellates) that belong to Family: Symbiodiniaceae (LaJeunesse et al., 2018). Symbiodiniaceae dinoflagellates contain inside their plastids a proteobacterial type of form II ribulose bisphosphate carboxylase/oxidase (form II RuBisCO), which is the key photosynthetic enzyme (Morse et al., 1995; Rowan et al., 1996). Consequently, animal-dinoflagellate associations, like scleractinian corals, symbiotic sea anemones and giant clams, are phototrophic and can flourish in nutrient-poor tropical waters (de Goeij et al., 2013). The host animal and its symbiotic dinoflagellates have a mutualistic relationship (Davy et al., 2012). While the host provides the symbionts with a protected environment as well as chemicals they need for photosynthesis, growth and reproduction, its photosynthesizing symbionts produce $\mathrm{O}_{2}$ and help remove the host's metabolic wastes. Most importantly, the symbionts share with the host a substantial proportion of their photosynthate, which can fulfill the host's metabolic need to various degrees (Fitt et al., 1986; Muscatine, 1990; Houlbréque and Ferrier-Pagés, 2009).

Symbiotic dinoflagellates living in hospite have no access to the ambient seawater. Hence, the host animal needs to obtain $\mathrm{C}_{i}$, nitrogen $(\mathrm{N})$ and phosphorus $(\mathrm{P})$ from the external medium and furnish them to its symbionts in support of their growth and reproduction (Rees, 1991; Furla et al., 2005). As the availability of these nutrients is particularly important for the symbionts while conducting photosynthesis, the host animal must absorb these exogenous nutrients at higher rates in light than in darkness. As a consequence, the host's transporters partaking in the absorption and translocation of these nutrients must be regulated by some sort of light-responsive mechanisms, so that they can align with the symbionts' light-dependent physiological needs. Many host animals grow faster in light than in darkness, as they try to fully exploit the photosynthate supplied by the symbionts during illumination. Consequently, animal-dinoflagellate associations display many light-dependent phenomena distinctively different from non-photosymbiotic animals. These phenomena include physiological processes related to phototrophy, antioxidative defense, biomineralization, as well as the absorption of exogenous nutrients. Recent research on giant clams have demonstrated that most of these physiological processes can be enhanced by light and are supported by the host's enzymes and transporters.

Therefore, this review aims to examine the molecular mechanisms of light-dependent physiological phenomena in intact giant clam-dinoflagellate associations, with emphases on the mutualistic relationship between the host and its symbionts. It also attempts to highlight differences in the properties of the host's molecular mechanisms between giant clams and scleractinian corals. Bivalve molluscs and cnidarians belong to different phyla and display major differences in physiology. As a mutualistic association between two organisms entails the interaction and integration of physiology between the animal host and its symbionts, the host's mechanisms participating in a specific light-dependent physiological process could be different between giant clams and symbiotic cnidarians. In comparison with corals, giant clams have more complex tissues and organs and display considerable degrees of division of labor among them. Consequently, light-enhanced phenomena in giant clams often involve the collaboration of two or more organs, which are connected by the hemolymph despite being physically separated.

In this review, gene nomenclature is presented in upper case and italicized (e.g., GS for the gene glutamine synthetase), while protein nomenclature is presented in the same way as the gene symbol but non-italicized (e.g., GS).

\section{GIANT CLAMS HARBOR EXTRACELLULAR SYMBIONTS IN A TUBULAR SYSTEM}

Unlike scleractinian corals, which harbor their symbionts in intracellular symbiosomes encircled by a host-derived membrane (Davy et al., 2012), giant clams host their symbionts extracellularly inside a fluid-filled and branched tubular system that is surrounded by hemolymph (Norton et al., 1992). Because of the extracellular location, the volume constraint on the symbiont's population inside the tubular system of giant clams could presumably be less critical than that on the symbionts living intracellularly inside symbiosomes of scleractinian corals. Due to the symbionts' extracellular location, substances supplied by the clam host must be translocated from the hemolymph through the basolateral and apical membranes of the tubular epithelial cells into the intra-tubular (luminal) fluid so that they can be accessed by the extracellular symbionts (Figure 1). Equally, photosynthate donated by the symbionts to the clam host must pass through the reverse route before they can reach the hemolymph.

The tubular system emanates as a single primary tube from the stomach. The primary tube branches into secondary and tertiary zooxanthellal tubules, the latter being mainly located in the tissues near the upper surface of the fleshy, colorful and extensible outer mantle (Norton et al., 1992). Hence, the outer mantle of giant clams contains a high density of symbionts 


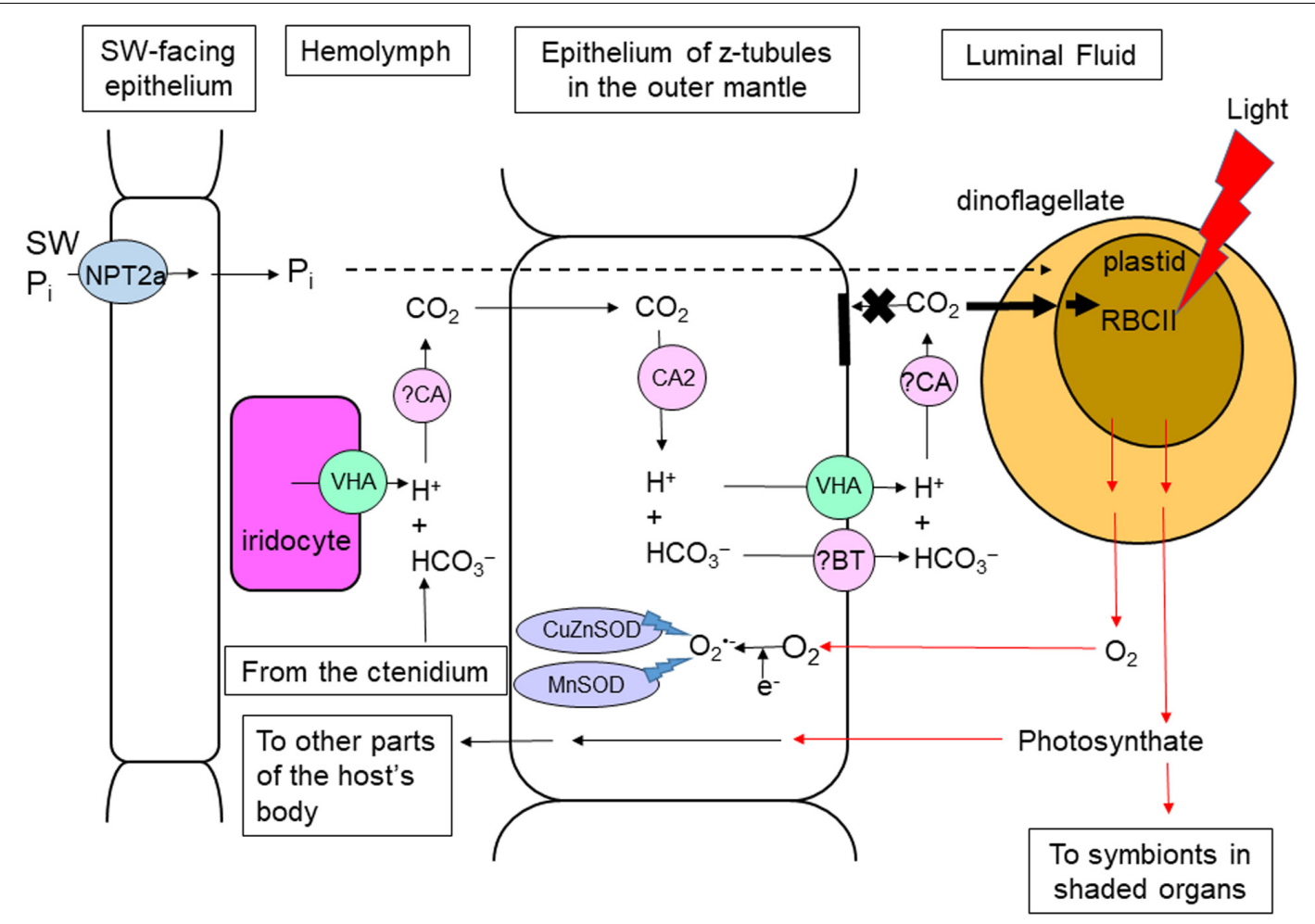

FIGURE 1 | Light-enhanced phenomena and the related mechanisms in the colorful outer mantle of Tridacna squamosa. Substances (e.g., inorganic carbon) supplied by the clam host to the extracellular symbiotic dinoflagellates residing inside the tertiary tubules of the outer mantle must be translocated from the hemolymph through the basolateral and apical membranes of the tubular epithelial cells into the intra-tubular (or luminal) fluid (black arrows). Photosynthate and $\mathrm{O}_{2}$ produced by the symbionts must go through the reverse route (red arrows) before they can reach the host's hemolymph. Illumination leads to a significant increase in the protein abundance of form II ribulose bisphosphate carboxylase/oxidase (RBCII) in these symbiotic dinoflagellates (Poo et al., 2020$)$. To supply CO 2 effectively to the photosynthesizing symbionts, the outer mantle of the host possesses a light-enhanced carbon concentration mechanism, which involves iridocytes and tubular epithelial cells, with Vacuolar-type $\mathrm{H}^{+}$-ATPase (VHA; Ip et al., 2018) and Carbonic Anhydrase 2 (CA2; Ip et al., 2017b) as the major catalytic mechanisms. Due to $\mathrm{O}_{2}$ released by the symbionts, the host needs to augment the detoxification of superoxide radicals $\left(\mathrm{O}_{2}{ }^{-}\right)$by increasing the expression levels of copper zinc superoxide dismutase (CuZnSOD; Hiong et al., 2018) and manganese superoxide dismutase (MnSOD; Chew et al., 2020) in the outer mantle in response to illumination. The host also conducts light-enhanced inorganic phosphate ( $\left.\mathrm{P}_{i}\right)$ absorption through Sodium-dependent Phosphate Transport protein 2a (NPT2a; Chan et al., 2020) and supply it to the photosynthesizing symbionts. ?BT: unidentified Bicarbonate Transporter. ?CA, unidentified Carbonic Anhydrase. SW, seawater. Z-tubule, zooxanthellal tubule.

(Griffiths and Klumpp, 1996), which can serve as large reservoirs of symbiotic dinoflagellates in the reef ecosystem (Umeki et al., 2020). In general, giant clams are associated with three genera of phototrophic dinoflagellates, Symbiodinium, Cladocopium, and Durusdinium (Hernawan, 2008; DeBoer et al., 2012; Ikeda et al., 2017; LaJeunesse et al., 2018; Lim et al., 2019). Recently, it has been reported that Tridacna maxima can also habor Gerakladium (Pochon et al., 2019). The structure of the tubular system (Norton et al., 1992) indicates that some symbiotic dinoflagellates can be present in organs inside the mantle cavity, which has been verified recently by Poo et al. (2020). However, only those symbionts residing in the outer mantle may be able to conduct photosynthesis efficiently, as only those tertiary tubules in the outer mantle are surrounded by iridocytes (Norton and Jones, 1992). Iridocytes contain stacks of tiny reflective platelets (Griffiths et al., 1992) that can scatter light of photosynthetically conducive wavelengths to the tertiary tubules and enhance the quantum of usable light reaching the symbionts by fivefold (Holt et al., 2014). They also back-reflect light of non-productive wavelengths, contributing in part to the distinctive coloration and pattern of the outer mantle of individual giant clams (Holt et al., 2014; Ghoshal et al., 2016). Iridocytes can also protect the symbionts against harmful short wavelength UV radiation by absorbing it and re-emitting radiation of longer wavelengths that are conducive for photosynthesis (Rossbach et al., 2020). Importantly, an iridocyte is a part of the host-mediated carbon concentration mechanism (CCM) that augments the supply of $\mathrm{C}_{i}$ to the photosynthesizing symbionts during illumination (Ip et al., 2018). In comparison, the quantum flux of light reaching the symbionts in other organs, which lack iridocytes and are shaded by the siphonal mantle, would presumably support only a low rate of photosynthesis.

Giant clams can be fully phototrophic and grow in Milliporefiltered seawater with light as the sole energy source for more than 10 months (Fitt and Trench, 1981). This is a feat that has not been demonstrated in scleractinian corals. Without food, the clam host must obtain all the organic nutrients needed from its phototrophic symbionts (Klumpp and Griffiths, 1994). In fact, 
the photosynthate supplied by symbiotic dinoflagellates can fully satisfy the metabolic requirements of Tridacna squamosa (Trench et al., 1981), Tridacna derasa (Klumpp and Lucas, 1994), Tridacna tevoroa (Klumpp and Lucas, 1994), and Tridacna gigas (Fisher et al., 1985; Mingoa, 1988; Klumpp et al., 1992). Furthermore, giant clams can efficiently absorb inorganic and organic nutrient from seawater through their ctenidia that have enormous surface area. By contrast, mixotrophy is important to most cnidarian-dinoflagellate associations, probably because they lack a dedicated organ for the absorption of exogenous nutrients. It has been estimated that partial heterotrophy can contribute to $15-35 \%$ of the daily metabolic requirement and $0-66 \%$ of the fixed carbon incorporated into the skeleton (Houlbréque and Ferrier-Pagés, 2009) of scleractinian corals.

\section{ILLUMINATION ENHANCES THE ACTIVITIES OF SOME ENZYMES AND TRANSPORTERS IN CERTAIN ORGANS OF T. squamosa}

Light can induce changes in activities of $\mathrm{Na}^{+} / \mathrm{K}^{+}$-ATPase (NKA) and Vacuolar-type $\mathrm{H}^{+}$-ATPase (VHA) in the inner mantle and the ctenidium of $T$. squamosa (Ip et al., 2015). Due to an increase in the effectiveness of $\mathrm{NH}_{4}{ }^{+}$to substitute for $\mathrm{K}^{+}$in the activation of $\mathrm{NKA}$, the $\mathrm{Na}^{+} / \mathrm{NH}_{4}{ }^{+}$-activatedNKA activity increases significantly in the extract obtained from the inner mantle of $T$. squamosa exposed to light, as compared with the control kept in darkness (Ip et al., 2015). Additionally, illumination leads to a significant decrease in the activity of $\mathrm{N}$-ethylmaleimide (NEM)-sensitive- $\mathrm{V}-\mathrm{H}^{+}$ATPase (VATPase) in the inner mantle. On the other hand, light exposure results in significant increases in the $\mathrm{Na}^{+} / \mathrm{K}^{+}$activated-NKA, $\mathrm{H}^{+} / \mathrm{NH}_{4}{ }^{+}$-activated- $\mathrm{H}^{+} / \mathrm{K}^{+}$-ATPase and NEMsensitive-VATPase activities in the extract obtained from the ctenidium of T. squamosa (Ip et al., 2015). Thus, Ip et al. (2015) have concluded that $\mathrm{Na}^{+}$homeostasis and acid/base balance in the hemolymph of $T$. squamosa are perturbed by light-enhanced shell formation. They have also postulated that light-enhanced shell formation in T. squamosa may involve the active uptake of ammonia from the environment (Ip et al., 2015), as ammonia can take part in the removal of $\mathrm{H}^{+}$generated in the extrapallial fluid during light-enhanced shell formation (Ip et al., 2006).

Enzymes and transporters can be regulated at the transcriptional, translational, and post-translational levels. Phototrophic organisms can respond to light, and plants display $>1.75$-fold diurnal changes in transcript levels of $>20 \%$ of the genes related to photosynthesis (Blasing et al., 2005). As giant clam-dinoflagellate associations are phototrophic, the possibility of illumination affecting the transcript and protein expression levels of enzymes and transporters of the clam host cannot be ignored. Indeed, the transcript levels and protein abundances of many host's transporters and enzymes in $T$. squamosa are light-dependent as they can be up- or down-upregulated by illumination (Table 1), even though the possibilities of concomitant regulation through post-translational modification and allosteric control cannot be ruled out at present.

\section{PHOTOSYNTHESIS CONDUCTED BY THE SYMBIOTIC DINOFLAGELLATES OF THE OUTER MANTLE IS FOUNDATIONAL TO OTHER LIGHT-DEPENDENT PHENOMENA}

Photosynthesis in the symbiotic dinoflagellates is of fundamental importance for fulfilling the metabolic demands of the giant clam-dinoflagellate association (Yellowlees et al., 1993; Leggat et al., 2002). Therefore, light-enhanced $C_{i}$ fixation by symbionts residing in the colorful outer mantle is the essential cause of other light-enhanced processes in the host. Dinoflagellates conduct C3 photosynthesis (Streamer et al., 1993), and rely on form II RuBisCO to fix $\mathrm{C}_{i}$ through the Calvin cycle (Rowan et al., 1996; Mayfield et al., 2014). Some of the carbohydrates produced by these photosynthesizing dinoflagellates can be utilized to synthesize essential and non-essential amino acids, while some can be released into the intra-tubular fluid of the tubular system to be shared with symbionts living in other host's organs located inside the mantle cavity (Figures 1, 2). Some of the photosynthate released into the intra-tubular fluid can be translocated across the tubular epithelium to the hemolymph to benefit the host (Figures 1, 2).

Using ethanol treatment as well as differential interference contrast and fluorescence (red channel) microscopy, Poo et al. (2020) have demonstrated the presence of symbiotic dinoflagellates in five organs (colorful outer mantle, whitish inner mantle, ctenidium, hepatopancreas and foot muscle) of T. squamosa obtained from Vietnam. They have also made pioneering attempts to estimate the phototrophic potential of symbiotic dinoflagellates in these five organs by determining the transcript levels of zooxanthellal form II RuBisCO (Zoox-rbcII) using quantitative real-time PCR (qPCR). Based on information available in multiple databases for Symbiodinium, Cladocopium, and Durusdinium (Bayer et al., 2012; Rosic et al., 2015; Aranda et al., 2016; Levin et al., 2016; Liew et al., 2016; Shoguchi et al., 2018), Poo et al. (2020) have successfully designed a set of qPCR primers that could react comprehensively with all rbcII sequences derived from these symbiotic dinoflagellates. They have subsequently used this set of primers to estimate the phototrophic potential of symbiotic dinoflagellates in the five organs of T. squamosa exposed to a $12 \mathrm{~h}$ light: $12 \mathrm{~h}$ dark regime, with an underwater irradiance of $120 \mu \mathrm{mol}$ photons $\mathrm{m}^{-2} \mathrm{~s}^{-1}$ (PPFD) at the level of the giant clams. In the Red Sea, T. squamosa is usually found at depths ranging from 11 to $20 \mathrm{~m}$ (Juinio et al., 1989; Andréfouët et al., 2014), although some mature individuals can be found as deep as $42 \mathrm{~m}$ (Jantzen et al., 2008). At a depth of $\sim 20 \mathrm{~m}$, Jantzen et al. (2008) estimated that T. squamosa would be exposed to $128 \pm 59 \mu \mathrm{mol}$ photons $\mathrm{m}^{-2} \mathrm{~s}^{-1}$. Although the actual light levels received by the giant clam individuals in waters of the Red Sea and Vietnam waters may be different, results obtained by 
TABLE 1 | Responses of the transcript level and protein abundance of various transporters and enzymes, derived from the clam host or the symbiotic dinoflagellates, in different organs of Tridacna squamosa during $12 \mathrm{~h}$ of exposed to light as compared with the control exposed to $12 \mathrm{~h}$ of darkness.

\begin{tabular}{|c|c|c|c|c|c|}
\hline Organ & $\begin{array}{l}\text { Origin (symbiotic } \\
\text { dinoflagellates or } \\
\text { clam host) }\end{array}$ & Transporters/enzymes & $\begin{array}{l}\text { Response to light: } \\
\text { transcript level }\end{array}$ & $\begin{array}{l}\text { Response to } \\
\text { light: protein } \\
\text { abundance }\end{array}$ & References \\
\hline \multirow[t]{7}{*}{ Outer mantle } & Symbiont & $\begin{array}{l}\text { Form II ribulose bisphosphate } \\
\text { carboxylase/oxidase }\end{array}$ & No change & Increase & Poo et al., 2020 \\
\hline & Symbiont & Urease & No change & Increase & Ip et al., 2020b \\
\hline & Host & Vacuolar-type $\mathrm{H}^{+}$-ATPase & Increase & Increase & Ip et al., 2018 \\
\hline & Host & Carbonic anhydrase 2 & No change & Increase & Ip et al., 2017b \\
\hline & Host & Manganese superoxide dismutase & Increase & Increase & Hiong et al., 2018 \\
\hline & Host & Copper zinc superoxide dismutase & No change & Increase & Chew et al., 2020 \\
\hline & Host & $\begin{array}{l}\text { Sodium-dependent phosphate } \\
\text { transport protein } 2 \mathrm{a}\end{array}$ & No change & Increase & Chan et al., 2020 \\
\hline \multirow[t]{10}{*}{ Inner mantle } & Symbiont & $\begin{array}{l}\text { Form II ribulose bisphosphate } \\
\text { carboxylase/oxidase }\end{array}$ & No data & No change & Poo et al., 2020 \\
\hline & Symbiont & Urease & Increase & Increase & Ip et al., 2020b \\
\hline & Host & Copper zinc superoxide dismutase & No change & Increase & Chew et al., 2020 \\
\hline & Host & Plasma Membrane $\mathrm{Ca}^{2+}$-ATPase & Increase & Increase & Ip et al., 2018 \\
\hline & Host & $\mathrm{Na}^{+} / \mathrm{Ca}^{2}+$ exchanger 3 & Increase & Increase & Boo et al., 2019 \\
\hline & Host & Sarcoplasmic reticulum $\mathrm{Ca}^{2+}$-ATPase & No change & Increase & Chan et al., 2020 \\
\hline & Host & $\mathrm{Na}^{+} / \mathrm{K}^{+}$-ATPase & Decrease & Increase & Boo et al., 2017 \\
\hline & Host & Carbonic anhydrase 4 & No change & Increase & Chew et al., 2019 \\
\hline & Host & Carbonic anhydrase 2 & Increase & Increase & Chew et al., 2019 \\
\hline & Host & Beta $\mathrm{Na}^{+} / \mathrm{H}^{+}$exchanger & No change & Increase & Cao-Pham et al., 2019a \\
\hline \multirow[t]{13}{*}{ Ctenidium } & Symbiont & $\begin{array}{l}\text { Form II ribulose bisphosphate } \\
\text { carboxylase/oxidase }\end{array}$ & No data & No change & Poo et al., 2020 \\
\hline & Symbiont & Urease & No change & No data & Ip et al., 2020b \\
\hline & Host & Dual-domain carbonic anhydrase & Increase & Increase & Koh et al., 2018 \\
\hline & Host & Vacuolar-type $\mathrm{H}^{+}$-ATPase & No change & Increase & Ip et al., 2018 \\
\hline & Host & $\mathrm{Na}^{+} / \mathrm{H}^{+}$exchanger 3 & Increase & Increase & Hiong et al., 2017a \\
\hline & Host & L-type voltage-gated $\mathrm{Ca}^{2+}$ channel & No change & Increase & Cao-Pham et al., 2019b \\
\hline & Host & Sarcoplasmic reticulum $\mathrm{Ca}^{2+}$-ATPase & Decrease & Increase & Chan et al., 2020 \\
\hline & Host & Glutamine synthetase & Increase & Increase & Hiong et al., 2017b \\
\hline & Host & Ammonia transporter 1 & Decrease & Decrease & Boo et al., 2018 \\
\hline & Host & $\mathrm{H}^{+}: 2 \mathrm{NO}_{3}-$ cotransporter, SIALIN & Increase & Increase & Ip et al., 2020a \\
\hline & Host & Urea-proton symporter, DUR3 & No change & Increase & Chan et al., 2018 \\
\hline & Host & $\mathrm{Na}^{+}:$glucose cotransporter 1 & No change & Increase & Chan et al., 2019 \\
\hline & Host & $\begin{array}{l}\text { Sodium-dependent phosphate } \\
\text { transport protein } 2 \mathrm{a}\end{array}$ & No change & No change & Chan et al., 2020 \\
\hline \multirow[t]{2}{*}{ Foot muscle } & Symbiont & $\begin{array}{l}\text { Form II ribulose bisphosphate } \\
\text { carboxylase/oxidase }\end{array}$ & No data & No change & Poo et al., 2020 \\
\hline & Symbiont & Urease & Increase & Increase & Ip et al., 2020b \\
\hline \multirow[t]{2}{*}{ Hepatopancreas } & Symbiont & $\begin{array}{l}\text { Form II ribulose bisphosphate } \\
\text { carboxylase/oxidase }\end{array}$ & No data & No change & Poo et al., 2020 \\
\hline & Symbiont & Urease & No change & No data & Ip et al., 2020b \\
\hline
\end{tabular}

Poo et al. (2020) probably reflect the full phototrophic potential of symbiotic dinoflagellates in the outer mantle of T. squamosa as they have been exposed to $120 \mu \mathrm{mol}$ photons $\mathrm{m}^{-2} \mathrm{~s}^{-1}$ of underwater irradiance.

Predictably, the outer mantle of T. squamosa has the greatest quantity of symbionts and much higher transcript level of Zoox$r b c I I$ than the other four organs located inside the mantle cavity (Poo et al., 2020). Illumination has no significant effect on the gene expression of Zoox-rbcII in the outer mantle probably because of its high background transcript level $\left(\times 10^{6}\right.$ copies per ng RNA). Nonetheless, light exposure leads to a significant increase in the protein abundance of Zoox-RBCII in the outer mantle (Poo et al., 2020), indicating that Zoox-RBCII could be regulated at the translational level (Table 1). It also indicates that illumination could increase the potential of $\mathrm{CO}_{2}$ fixation in the outer mantle (Figure 1). By contrast, the protein abundance of Zoox-RBCII remains unchanged in the other four shaded organs during $12 \mathrm{~h}$ of illumination (Poo et al., 2020).

In a separate study, Poo et al. (2021) have obtained from the symbiotic dinoflagellates of $T$. squamosa three 


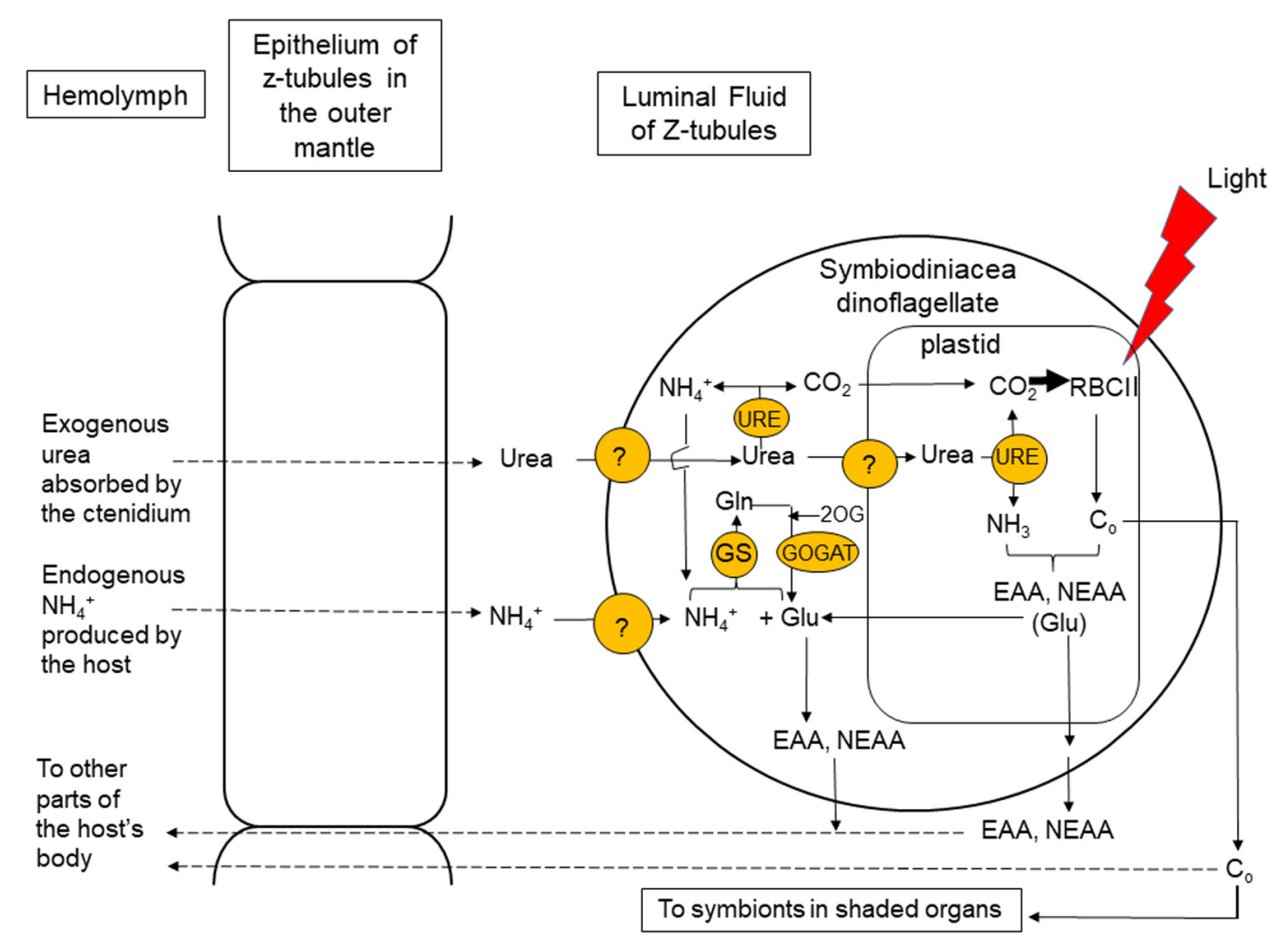

FIGURE 2 | Coupling of photosynthesis and nitrogen $(\mathrm{N})$ assimilation leading to amino acid synthesis in the symbiotic dinoflagellates residing in the colorful outer mantle of $T$. squamosa. Urea is a good source of $\mathrm{N}$ and $\mathrm{CO}_{2}$ for symbiotic dinoflagellates, which possess urease (URE) to catalyze the degradation of urea. URE is localized in the plastid, where it can facilitate the effective harness of urea-carbon and urea- $\mathrm{N}$ for photosynthesis and amino acid synthesis, respectively (Ip et al., 2020b). URE is also localized in the dinoflagellates' cytoplasm, where it can degrade some of the absorbed urea to ammonia. $\mathrm{The}$ ammonia $\left(\mathrm{NH}_{4}{ }^{+}\right)$released and glutamate (Glu) can be utilized by the cytosolic Glutamine Synthetase (GS) to synthesize glutamine (Gln), which plays a central role in the syntheses of nucleic acids. Glu can be replenished by a reaction catalyzed by Glutamine 2-Oxoglutarate Amidotransferase (GOGAT), which utilizes Gln and 2-oxoglutarate (2OG) as substrates (Fam et al., 2018). With the GS:GOGAT cycle, symbiotic dinoflagellates can absorb and metabolize $\mathrm{NH}_{4}{ }^{+}$generated endogenously by the host to produce Glu, which can be used for amino acid synthesis. Symbiotic dinoflagellates need to supply the host with essential amino acids (EAA) and non-essential amino acids (NEAA) for its growth and development. $\mathrm{C}_{0}$, organic carbon. Z-tubule, zooxanthellal tubule. ?: unidentified transporters.

coding cDNA sequences of one tandem repeat of rbcII for Symbiodinium (Symb-rbcII), Cladocopium (Clad-rbcII), and Durusdinium (Duru-rbcII). Each of these coding sequences consists of $1,458 \mathrm{bp}$, which can be translated into a protein of 485 amino acids. Based on these three rbcII sequences and those available in various dinoflagellate databases, Poo et al. (2021) have successfully designed three sets of qPCR primers that can differentiate Symb-rbcII, Clad-rbcII, and Duru$r b c I I$, and used them to determine the relative abundances of Symbiodinium, Cladocopium, and Durusdinium in the five organs (outer mantle, inner mantle, foot muscle, ctenidium and hepatopancreas) of T. squamosa. They have demonstrated that Durusdinium is the dominant genus of symbiont present in individuals of T. squamosa obtained from Vietnam (Poo et al., 2021). Furthermore, the proportion of Symb-rbcII, Clad$r b c I I$ and Duru-rbcII, and hence the phototrophic potentials of Symbiodinium, Cladocopium, and Durusdinium, fluctuate along the length of the outer mantle and among the five organs of T. squamosa (Poo et al., 2021). By performing in vitro experiment on symbiotic dinoflagellates freshly isolated from the outer mantle of T. squamosa, Poo et al. (2021) have demonstrated that Symbiodinium, Cladocopium, and Durusdinium display different responses to light with regard to the transcriptional regulation of $r b c I I$ expression. Their results corroborate the proposition that different lineages of Symbiodiniaceae can have distinct photobiology and photosynthetic efficiency (Iglesias-Prieto et al., 2004). Hence, the clam host may gain distinct physiological advantages by association with a certain genus and/or species of dinoflagellate under certain environmental conditions (Fitt et al., 1986; Belda-Baillie et al., 1999; DeBoer et al., 2012; Ikeda et al., 2017).

\section{THE ALIGNMENT OF $\mathrm{C}_{i}$ FIXATION AND N ASSIMILATION IN SYMBIOTIC DINOFLAGELLATES OF THE OUTER MANTLE}

Symbiotic dinoflagellates play an indispensable role in not only $\mathrm{C}_{i}$ fixation (Yellowlees et al., 1993) but also $\mathrm{N}$ assimilation 
(Rees et al., 1994), and these two processes need to be coupled because $\mathrm{N}$ assimilation requires a supply of carbon-chains. Urea $\left(\mathrm{NH}_{2} \mathrm{CONH}_{2}\right)$ contains two $\mathrm{N}$ atoms and is therefore a good source of $\mathrm{N}$ for organisms that possess the enzyme to degrade it. Urease (URE) is a metalloenzyme that catalyzes the breakdown of urea to $\mathrm{NH}_{3}$ and $\mathrm{CO}_{2}$ through a onestep reaction, $\left(\mathrm{NH}_{2}\right)_{2} \mathrm{CO}+\mathrm{H}_{2} \mathrm{O} \rightarrow \mathrm{CO}_{2}+2 \mathrm{NH}_{3}$ (Dhup et al., 2016). Animals generally lack URE (Campbell, 1991) and therefore excrete urea as a nitrogenous waste. However, T. squamosa conducts light-enhanced urea absorption instead (Chan et al., 2018). The absorbed urea must be delivered to the symbionts for assimilation because it cannot be metabolized by the host. Besides having the highest phototrophic potential (Poo et al., 2020), the outer mantle of T. squamosa also expresses the highest transcript level of zooxanthellal URE (ZooxURE), which is derived comprehensively from Symbiodinium, Cladocopium, and Durusdinium, among the five organs studied (Ip et al., 2020b). This is expected as the outer mantle has the greatest quantity of symbiotic dinoflagellates and receives the greatest irradiance. Notably, the ratio of Zoox-URE/ZooxrbcII in the outer mantle of T. squamosa is significantly higher than those in the other four organs, indicating that symbionts in the outer mantle have the greatest potential to assimilate urea- $\mathrm{N}$ with reference to their photosynthetic potential. It is also supportive of a functional relationship between urea degradation and carbon-fixation in these symbionts in the outer mantle (Figure 2). Indeed, illumination up-regulates the protein abundance of Zoox-URE, despite the transcript level of Zoox$U R E$ remains unchanged, in the outer mantle of T. squamosa (Table 1; Ip et al., 2020b), corroborating the proposition that the increased degradation of urea to release $\mathrm{NH}_{3}$ for amino acid synthesis is synchronized with light-enhanced $\mathrm{CO}_{2}$ fixation (Figure 2).

Zoox-URE is strongly immunolocalized in the plastids of symbiotic dinoflagellates located in the outer mantle of T. squamosa (Ip et al., 2020b). Inside the plastid, urea-carbon and urea-N can be harnessed effectively for photosynthesis and amino acid synthesis, respectively (Figure 2). The carbohydrates and amino acids produced can be supplied to the host in support of its protein synthesis, growth, and development. Zoox-URE is also detected moderately in the dinoflagellates' cytoplasm, where it can facilitate the degradation of some of the absorbed urea to ammonia. The ammonia released can be used as a substrate by the cytosolic GS to synthesize glutamine, which plays a central role in nucleic acid synthesis (Figure 2). Of note, a novel GS has been identified from dinoflagellates residing in the outer mantle of T. squamosa (Fam et al., 2018). The cDNA coding sequence of this novel GS comprises 2325 bp, encoding 774 amino acids with a molecular mass of $85 \mathrm{kDa}$. It is longer than other GSs and displays the characteristics of both GS1 and nucleotide diphosphate kinase. The glutamate needed for glutamine formation through GS can be supplied by the reaction catalyzed by glutamine 2-oxoglutarate amidotransferase (GOGAT), which uses glutamine and 2-oxoglutarate as substrates (Fam et al., 2018). Furthermore, Zoox-URE is detected weakly in the cell wall and plasma membrane of these dinoflagellates. The localization of Zoox-URE in the plasma membrane may facilitate the release of ammonia from urea in close proximity to ammonia transporters/channels to facilitate ammonia absorption.

\section{THE HOST CAN SUPPLY $\mathrm{CO}_{2}$ EFFICIENTLY TO THE PHOTOSYNTHESIZING SYMBIONTS THROUGH A LIGHT-ENHANCED CCM IN THE OUTER MANTLE}

$\mathrm{HCO}_{3}{ }^{-}$is the main form of $\mathrm{C}_{i}$ present in the hemolymph of giant clams (Rees et al., 1993). $\mathrm{HCO}_{3}{ }^{-}$circulating in the hemolymph must be absorbed into the epithelial cells of the zooxanthellal tubules through the basolateral (hemolymph-facing) membranes. Then, it must be transported across the apical (lumen-facing) membranes of these epithelial cells to the intra-tubular fluid, so that it can be absorbed by the extracellular symbionts. To augment the translocation of $\mathrm{C}_{i}$ from the hemolymph to the intra-tubular fluid, the host possesses a light-dependent CCM (Figure 1) in the outer mantle, which involves VHA (Ip et al., 2018) and Carbonic Anhydrase 2 (CA2; Ip et al., 2017b) of the tubular epithelial cells and iridocytes.

Vacuolar-type $\mathrm{H}^{+}$-ATPase is an ATP-driven multi-subunit enzyme and electrogenic transporter. It transports $\mathrm{H}^{+}$actively and generates an $\mathrm{H}^{+}$electrochemical potential gradient across biomembranes (Mindell, 2012). When incorporated into the plasma membrane, it can actively transport $\mathrm{H}^{+}$out of the cell, and the $\mathrm{H}^{+}$gradient produced can be used by $\mathrm{H}^{+}$-dependent symporters or antiporters to drive a variety of secondary active transport processes (Tresguerres, 2016). Structurally, VHA comprises two complexes and 14 protein subunits (Cotter et al., 2015). There are eight different subunits (designated as ' $\mathrm{A}$ ' to ' $\mathrm{H}$ ') in the cytoplasmic $\mathrm{V}_{1}$ complex, with subunits $\mathrm{A}$ and $\mathrm{B}$ acting together to hydrolyze ATP. The cDNA coding sequence of a host-derived VHA subunit A (ATP6V1A) has been cloned from T. squamosa (Ip et al., 2018). Exposure of T. squamosa to light leads to significant increases in the transcript and protein expression levels of ATP6V1A/ATP6V1A in the outer mantle (Table 1). Iridocytes in the outer mantle are also strongly ATP6V1A-immunopositive (Ip et al., 2018). They can probably increase the secretion of $\mathrm{H}^{+}$to the hemolymph and to promote the dehydration of $\mathrm{HCO}_{3}{ }^{-}$to $\mathrm{CO}_{2}$ during illumination (Figure 1). Then, $\mathrm{CO}_{2}$ can be transported into epithelial cells of the zooxanthellal tubules across their basolateral membrane. This explains why the $\left[\mathrm{C}_{i}\right]$ in the hemolymph would decrease from 1.8 to $0.8 \mathrm{mM}$ during illumination (Leggat et al., 1999). As iridocytes are present only in the outer mantle of giant clams, organs that lack iridocytes might not be able to translocate $\mathrm{CO}_{2}$ efficiently from the hemolymph into the tubular epithelial cells.

$\mathrm{CO}_{2}$ and $\mathrm{HCO}_{3}{ }^{-}$interconverts through the reaction $\mathrm{CO}_{2}+\mathrm{H}_{2} \mathrm{O} \rightleftharpoons \mathrm{HCO}_{3}^{-}+\mathrm{H}^{+}$, which can be accelerated by carbonic anhydrases (CAs; Supuran, 2008). The $\mathrm{CO}_{2}$ that has entered the epithelial cells of the zooxanthellal tubules of T. squamosa can be converted back to $\mathrm{HCO}_{3}{ }^{-}$, because these cells contain a cytoplasmic carbonic anhydrase 2 (CA2; Ip et al., 2017b). In the outer mantle of T. squamosa, CA2 is localized in 
the cytoplasm of epithelial cells lining the tertiary tubules that contain the extracellular symbionts (Figure 1). Although the transcript level of $C A 2$ remains unchanged during light exposure, the protein abundance of CA2 increases by $\sim 2$-fold in the outer mantle of $T$. squamosa exposed to $12 \mathrm{~h}$ of light as compared with the control kept in darkness (Table 1). Hence, there could be an increase in the capacity to hydrate $\mathrm{CO}_{2}$ to $\mathrm{HCO}_{3}{ }^{-}$in the epithelial cells of the zooxanthellal tubules during illumination (Ip et al., 2017b). The $\mathrm{HCO}_{3}{ }^{-}$formed inside these epithelial cells must permeate the apical membrane through some kind of $\mathrm{HCO}_{3}{ }^{-}$transporter, which has not been identified.

Nevertheless, the intra-tubular fluid in the zooxanthellal tubules needs to have a high level of $\mathrm{PCO}_{2}$, and not high $\left[\mathrm{HCO}_{3}{ }^{-}\right]$, in order to support photosynthesis in the symbionts. This is because dinoflagellates freshly isolated from giant clams absorb mainly $\mathrm{CO}_{2}$ for photosynthesis (Yellowlees et al., 1993). Thus, $\mathrm{HCO}_{3}{ }^{-}$must undergo dehydration to form $\mathrm{CO}_{2}$ in the intra-tubular fluid, and this requires an increased supply of $\mathrm{H}^{+}$to drive the dehydration reaction in the lumen during illumination. In order to achieve a high level of $\mathrm{PCO}_{2}$, the apical membranes of the tubular epithelial cells must be relatively impermeable to $\mathrm{CO}_{2}$, so that a back diffusion of $\mathrm{CO}_{2}$ into the epithelial cells would not occur (Figure 1). Notably, ATP6V1A is also localized in the apical membrane of the tubular epithelial cells, indicating that VHA is well-positioned to secrete $\mathrm{H}^{+}$from these epithelial cells into the lumen (Ip et al., 2018). Overall, the host-mediated and light-enhanced CCM of the outer mantle can augment the supply of $\mathrm{CO}_{2}$ to the photosynthesizing symbionts, although the symbionts would probably need to possess their own CCM in order to regulate the uptake of $\mathrm{CO}_{2}$.

Scleractinian corals also express a host VHA at the endomembrane surrounding the symbiosome of gastrodermal cells (Barott et al., 2015). Presumably, its operation would acidify the symbiosome interior to $\sim \mathrm{pH} 4$ and augment the conversion of $\mathrm{HCO}_{3}{ }^{-}$to $\mathrm{CO}_{2}$ to facilitate the uptake of $\mathrm{CO}_{2}$ by the symbionts. However, symbiotic dinoflagellates isolated from corals utilize predominantly $\mathrm{HCO}_{3}{ }^{-}$(Goiran et al., 1996) instead of $\mathrm{CO}_{2}$ as in the case of dinoflagellates isolated from giant clams (Yellowlees et al., 1993). Notably, the origin and molecular property of the type of $\mathrm{CA}$ involved in $\mathrm{HCO}_{3}{ }^{-}$dehydration in the symbiosome of scleractinian corals have not been elucidated. Furthermore, whether illumination would affect the gene and protein expression levels of VHA in scleractinian corals remains unknown at present.

\section{THE OUTER MANTLE NEEDS LIGHT-ENHANCED ANTI-OXIDATIVE DEFENSE MECHANISMS TO DEAL WITH $\mathrm{O}_{2}$ PRODUCED BY PHOTOSYNTHESIZING SYMBIONTS}

Increased production of reactive oxygen species (ROS), including superoxide radical $\left(\mathrm{O}_{2}^{-}\right)$, can occur in photosynthesizing dinoflagellates during illumination (Foyer, 2018). ROS can attack biomolecules and affect the rate of senescence (Hermes-Lima,
2004). Consequently, giant clams must possess mechanisms that can detoxify $\mathrm{O}_{2}{ }^{-}$, and the anti-oxidative defense must be more vigorous in light than in darkness (Hiong et al., 2018; Chew et al., 2020). In giant clams, ROS leaking from the photosynthesizing symbionts are unlikely to affect the oxidative status of the host cells directly, because the symbionts are located extracellularly inside the tubular system (Figure 1). Despite that, photosynthesizing symbionts can produce large amounts of $\mathrm{O}_{2}$, which can be released into the intra-tubular fluid. The released $\mathrm{O}_{2}$ can permeate the tubular epithelium into the hemolymph, which can be supersaturated with $\mathrm{O}_{2}$ and contains $\mathrm{O}_{2}$ bubbles during illumination (Leggat et al., 1999). Thus, tissues of the clam host can be affected by hyperoxia, as the steep $\mathrm{PO}_{2}$ gradient can drive $\mathrm{O}_{2}$ into the host cells. Inside the cytoplasm, $\mathrm{O}_{2}$ can react with electrons leaked out from mitochondria to form $\mathrm{O}_{2} \cdot-$ (Bandyopadhyay et al., 1999). In addition, increased generation of ROS can occur inside mitochondria due to increases in the availability of $\mathrm{O}_{2}$ and the demand of energy for cellular activities. As follows, the host's organs, particularly the outer mantle, would need to defend against plausible oxidative damages by ROS in the cytoplasm and in the mitochondria. Obviously, in order to align with the photosynthetic activity of its symbionts, the host's antioxidative defense mechanisms must be either light-responsive or $\mathrm{O}_{2}$-responsive, or both.

Superoxide dismutases (SODs) are enzymes that scavenge $\mathrm{O}_{2} \cdot-$ intracellularly to ameliorate potential oxidative damage. They catalyze the dismutation of two molecules of $\mathrm{O}_{2}{ }^{-}$to $\mathrm{H}_{2} \mathrm{O}_{2}$, and $\mathrm{H}_{2} \mathrm{O}_{2}$ is subsequently detoxified to $\mathrm{H}_{2} \mathrm{O}$ and $\mathrm{O}_{2}$, catalyzed by catalase or glutathione peroxidase (Scandalios, 2005). Most eukaryotic cells express copper-zinc superoxide dismutases (CuZnSODs) in the cytoplasm (Sturtz et al., 2001) and manganese superoxide dismutases (MnSODs) in the mitochondrial matrix (Perry et al., 2010). Recently, the complete cDNA coding sequence of a host-derived CUZnSOD has been obtained from the outer mantle of the T. squamosa (Chew et al., 2020). The protein abundance, but not the transcript level, of CuZnSOD, increases significantly in the outer mantle of T. squamosa after $12 \mathrm{~h}$ of light exposure, indicating translational regulation of expression (Table 1; Chew et al., 2020). This would probably result in an increased capacity to detoxify $\mathrm{O}_{2}{ }^{-}$in the outer mantle during illumination. By contrast, the transcript level and protein abundance of CuZnSOD/CuZnSOD in the inner mantle, which contains only a small quantity of symbionts, are unaffected by illumination (Table 1). Thus, it can be concluded that the light-dependent increase in expression level of CuZnSOD in the outer mantle is needed to detoxify the ROS produced in the cytoplasm resulting from hyperoxia generated by the photosynthesizing symbionts (Figure 1). Moreover, the complete cDNA coding sequence of the host's MnSOD has been cloned from the outer mantle of $T$. squamosa (Hiong et al., 2018). In light, the metabolic rate of the outer mantle probably increases because of the increased supply of nutrients to the photosynthesizing symbionts and the receipt of $\mathrm{O}_{2}$ and photosynthate from them. This can lead to increases in the production of ROS in the mitochondria. Thus, exposure to light for $12 \mathrm{~h}$ leads to significant increases in the transcript level and protein abundance of $M n S O D / M n S O D$ in the outer 
mantle of T. squamosa (Table 1; Hiong et al., 2018), in order to detoxify excess mitochondrial $\mathrm{O}_{2}{ }^{-}$and to prevent oxidative damage (Figure 1).

\section{LIGHT-ENHANCED $C_{i}$ ABSORPTION IN THE CTENIDIUM TO SUPPORT PHOTOSYNTHESIS AND SHELL FORMATION}

During illumination, the demand of $\mathrm{C}_{i}$ by the giant clamdinoflagellate association is high because of the augmentation of two $C_{i}$-dependent processes: photosynthesis in the symbiotic dinoflagellates and shell formation in the host (Figure 2). It has been established that $\mathrm{CO}_{2}$ fixation by photosynthesizing symbionts alone can completely deplete $\mathrm{C}_{i}$ in the host's hemolymph in <13 $\mathrm{min}$ (Rees et al., 1993). There are two possible sources of $\mathrm{C}_{i}$ for the symbionts: metabolic $\mathrm{CO}_{2}$ produced by the host, and $\mathrm{C}_{i}$ absorbed by the host from the ambient seawater. In giant clams, the majority of $\mathrm{CO}_{2}$ fixed by the symbionts is derived from the latter (Rees et al., 1993). For T. squamosa, it has been shown that the host absorbs $\mathrm{C}_{i}$ through light-dependent mechanisms in its ctenidium (Figure 3). The ctenidium is primarily an organ for respiration and filter feeding in molluscs, but it may play relatively minor roles in $\mathrm{O}_{2}$ uptake and $\mathrm{CO}_{2}$ excretion in giant clams, particularly during the day. This is because photosynthesizing symbionts produce $\mathrm{O}_{2}$ inside the host and remove the host's metabolic $\mathrm{CO}_{2}$ during illumination. Nevertheless, due to its enormous surface area generated by numerous filaments and tertiary water channels, the ctenidium of giant clams can take part efficiently in the absorption of dissolved nutrients directly from the ambient seawater and the maintenance of acid-base balance. That could be one of the reasons why mixotrophy (or partial heterotrophy) is not vitally essential for giant clams' survival, as in the case of scleractinian corals. The ctenidial mechanisms of $\mathrm{C}_{i}$ uptake in $T$. squamosa include $\mathrm{Na}^{+} / \mathrm{H}^{+}$Exchanger 3 (NHE3; Hiong et al., 2017a), VHA (Ip et al., 2018), and Dual-Domain Carbonic Anhydrase (DDCA; Koh et al., 2018).

Recently, DDCA has been sequenced and characterized from the ctenidium of $T$. squamosa. Its cDNA coding sequence comprises $1,803 \mathrm{bp}$, which encodes a protein of 601 amino acids and $66.7 \mathrm{kDa}$ (Koh et al., 2018). The deduced DDCA sequence has a high similarity with the $70 \mathrm{kDa} C A$ from T. gigas (Leggat et al., 2002). It contains two distinct $\alpha$-CA domains, and each domain consists of a specific catalytic site. It also comprises two transmembrane regions (TMs), whereby the first TM is located inside the first CA domain, and the second TM is positioned near the end of the C-terminus. A glycosylphosphatidylinositol (GPI) lipid anchor (Ala576) can also be found near the $3^{\prime}$ end of the second CA domain. As the two catalytic sites are separated by a TM embedded in the plasma membrane, the one nearer to the $5^{\prime}$ end can be exposed to the external medium, and the other one closer to the $3^{\prime}$ end can be located in the cytoplasm. Based on immunofluorescence microscopy, DDCA has an apical localization in the epithelial cells surrounding the tertiary water channels and in certain epithelial cells near the base of the ctenidial filament. Therefore, the first catalytic domain of DDCA probably functions to dehydrate $\mathrm{HCO}_{3}{ }^{-}$to $\mathrm{CO}_{2}$ in the external medium, in order to augment the influx of exogenous $\mathrm{CO}_{2}$ into the cell down a favorable $P \mathrm{CO}_{2}$ gradient (Figure 3). As the $3^{\prime}$-end of the DDCA is attached to the plasma membrane through the second TM and the GPI anchor, the second catalytic domain is located in the cytoplasm in close proximity to the inner surface of the plasma membrane. Thus, the second catalytic domain can effectively catalyze the hydration of the absorbed $\mathrm{CO}_{2}$ back to $\mathrm{HCO}_{3}{ }^{-}$(Figure 3). The significant increases in the transcript and protein expression levels of DDCA/DDCA in the ctenidium of $T$. squamosa during illumination (Table 1) denote a possible increase in the potential of $C_{i}$ assimilation in the ctenidial epithelial cells to fulfill the increased need of $\mathrm{C}_{i}$ for photosynthesis and light-enhanced shell formation. The efflux of $\mathrm{HCO}_{3}{ }^{-}$from the ctenidial epithelial cells into the hemolymph probably involves an electrogenic $\mathrm{Na}^{+} / \mathrm{HCO}_{3}{ }^{-}$cotransporter (NBCe) yet to be identified.

$\mathrm{H}^{+}$is needed to promote the dehydration of $\mathrm{HCO}_{3}{ }^{-}$to $\mathrm{CO}_{2}$ in the ambient seawater during illumination, and the ctenidium of $T$. squamosa can excrete $\mathrm{H}^{+}$through VHA or NHE3 (Figure 3). The complete cDNA coding sequence of ATP6V1A has been obtained from the ctenidium of T. squamosa (Ip et al., 2018). Although the transcript level of ATP6V1A remains unchanged in the ctenidium of $T$. squamosa during light exposure, the protein abundance of ATP6V1A increases significantly by $\sim 2$-fold after $12 \mathrm{~h}$ of exposure to light as compared to the control, implying that it is regulated mainly at the translational level (Table 1; Ip et al., 2018). ATP6V1A has an apical localization in the epithelial cells of the ctenidial filaments and tertiary water channels, indicating that VHA is positioned to excrete $\mathrm{H}^{+}$to the external medium (Figure 3). The increase in protein abundance of ATP6V1A in the ctenidium of T. squamosa during light exposure (Ip et al., 2018) corroborates the report of Ip et al. (2015) on the increase in ctenidial NEM-sensitive VHA activity in response to light.

NHEs are transmembrane proteins that can regulate intracellular $\mathrm{pH}$ and ionic balance by mediating $\mathrm{Na}^{+}$influx and $\mathrm{H}^{+}$efflux at a 1:1 stoichiometry (Fliegel and Dibrov, 1996). The coding sequence of NHE3 has been obtained from the ctenidium of T. squamosa, and NHE3 has an apical localization in the epithelial cells of the ctenidial filaments and tertiary water channels (Hiong et al., 2017b). Additionally, the ctenidium of clams exposed to $12 \mathrm{~h}$ of light displays consistently stronger NHE3-immunofluorescence, as well as higher transcript level and protein abundance of NHE3/NHE3, than those of the control kept in darkness (Table 1; Hiong et al., 2017b). Hence, ctenidial NHE3 can also be involved in light-enhanced $\mathrm{H}^{+}$excretion in T. squamosa (Figure 3). As light-enhanced shell formation generates $\mathrm{H}^{+}$that needs to be removed from the extrapallial fluid where $\mathrm{CaCO}_{3}$ deposition occurs, the excess $\mathrm{H}^{+}$can be shuttled to the ctenidium for excretion through VHA and NHE3 (Figure 3). 


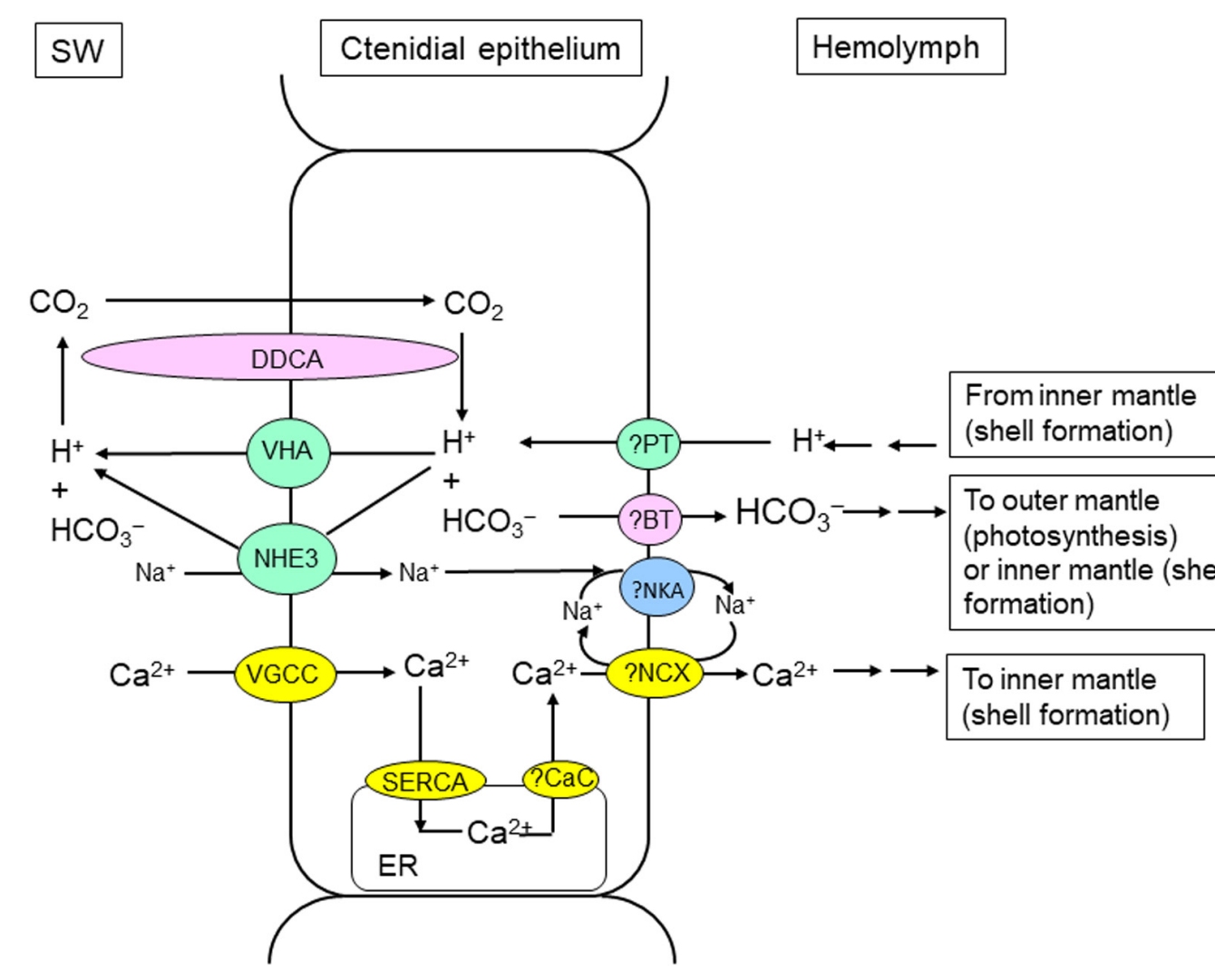

FIGURE 3 | Mechanisms of light-enhanced inorganic carbon $\left(\mathrm{C}_{i}\right)$ and calcium ion $\left(\mathrm{Ca}^{2+}\right)$ absorption in the ctenidium of $T$. squamosa. The clam host needs to absorb $\mathrm{C}_{i}$ from the ambient seawater to support photosynthesis in symbiotic dinoflagellates in the outer mantle and shell formation in the inner mantle. In T. squamosa, the host absorbs $\mathrm{C}_{i}$ through light-dependent mechanisms in its ctenidium. These mechanisms include $\mathrm{Na}^{+} / \mathrm{H}^{+}$Exchanger 3 (NHE3; Hiong et al., 2017a), Vacuolar-type H+-ATPase (VHA; Ip et al., 2018), and Dual-Domain Carbonic Anhydrase (DDCA; Koh et al., 2018). DDCA has an apical localization in the ctenidial epithelial cells. The active site of the first catalytic domain probably functions to dehydrate $\mathrm{HCO}_{3}{ }^{-}$to $\mathrm{CO}_{2}$ in the external medium to augment the permeation of $\mathrm{CO}_{2}$ into the epithelial cell down a favorable $\mathrm{PCO}_{2}$ gradient. The second catalytic domain of DDCA can effectively catalyze the hydration of the $\mathrm{CO}_{2}$ that has entered the cell back to $\mathrm{HCO}_{3}{ }^{-}$. As the increased dehydration of $\mathrm{HCO}_{3}{ }^{-}$to $\mathrm{CO}_{2}$ in the ambient seawater during illumination needs a supply of $\mathrm{H}^{+}$, the ctenidium of $T$. squamosa can excrete the excess $\mathrm{H}^{+}$generated during light-enhanced shell formation through VHA and NHE3. L-type Voltage-gated Ca ${ }^{2+}$ channel (VGCC) VGCC is well-positioned to absorb exogenous $\mathrm{Ca}^{2+}$ in the ctenidium of T. squamosa (Cao-Pham et al., 2019b), and the absorbed Ca ${ }^{2+}$ can be shuttled through the hemolymph to the inner mantle to support light-enhanced shell formation (see Figure 5). The ctenidium also expresses Sarcoplasmic reticulum $\mathrm{Ca}^{2+}$-ATPase, which pumps $\mathrm{Ca}^{2+}$ into the endoplasmic reticulum (ER) to maintain a low cytosolic $\left[\mathrm{Ca}^{2+}\right]$ in epithelial cells of the ctenidial filaments. ?BT, unidentified bicarbonate transporter (probably an electrogenic $\mathrm{Na}^{+} / \mathrm{HCO}_{3}{ }^{-}$cotransporter). ?CaC, unidentified calcium channel. ? $\mathrm{NCX}$, a type of $\mathrm{Na}^{+} / \mathrm{Ca}^{2+}$ exchanger yet to be identified. ?NKA, $\mathrm{Na}^{+} / \mathrm{K}^{+}$-ATPase yet to be cloned; ?PT, unidentified proton transporter. SW, seawater.

This signifies the importance of collaboration between the inner mantle and the ctenidium to achieve light-enhanced shell formation and light-enhanced $\mathrm{C}_{i}$ uptake.

\section{LIGHT-ENHANCED ABSORPTION AND ASSIMILATION OF EXOGENOUS N IN THE CTENIDIUM}

It has been suggested that the hosts of animal-dinoflagellate associations can control the symbiont's population through depriving them of $\mathrm{N}$ (Belda and Yellowlees, 1995; Cui et al., 2019). However, animals cannot synthesize all the twenty amino acids needed for survival, and they must generally obtain nine essential amino acids from the diet (Leuchtenberger et al., 2005). While the host animal can synthesize non-essential amino acids from exogenous and endogenous ammonia using carbon-chains supplied by photosynthesizing symbionts (Cui et al., 2019), it cannot produce the essential amino acids required for protein synthesis and muscle production. Therefore, besides controlling the symbiont's population, the host needs to play a balancing act to provide the symbionts with an optimized amount of $\mathrm{N}$ in order to receive from them the adequate quantities of essential amino acids needed for growth and development. In essence, $\mathrm{N}$-recycling in animal-dinoflagellate associations has two core elements: (1) the tightly regulated supply of not only ammonia but also other $\mathrm{N}$-containing compounds from the host to the symbionts, and (2) the donation of amino acids, particularly essential ones, from the symbionts to the host. As symbionts need a greater supply of $\mathrm{N}$ for amino acid synthesis while carbon-chains are produced through photosynthesis during illumination, the host must conduct light-enhanced absorption 
and assimilation of exogenous $\mathrm{N}$ in order to meet the symbionts' need. Nonetheless on the assumption that scleractinian corals put a greater emphasis on regulating the population of intracellular symbionts through limiting the supply of $\mathrm{N}$ to them, the host may not be able to receive an adequate provision of essential amino acids. That could be a contributing factor to why partial heterotrophy can increase protein concentration (Clayton and Lasker, 1984; Al-Moghrabi et al., 1995) and tissue synthesis (Anthony and Fabricius, 2000; Ferrier-Pagès et al., 2003; Houlbrèque et al., 2003, 2004) in scleractinian corals.

The degradation of excess amino acids produce toxic ammonia, and most aquatic animals excrete ammonia as the major nitrogenous waste (Ip and Chew, 2010; Chew and Ip, 2014). By contrast, animal-dinoflagellate associations do not excrete ammonia under normal circumstances but absorb and assimilate exogenous ammonia instead (Wilkerson and Muscatine, 1984; Wilkerson and Trench, 1986; Miller and Yellowlees, 1989). Giant clams absorb ammonia 5-18 times faster in light than in darkness (Fitt et al., 1993), and they excrete ammonia only after long periods of exposure to complete darkness (Muscatine and D'Elia, 1978; Wilkerson and Muscatine, 1984; Szmant and Gassman, 1990). The addition of inorganic N to the ambient seawater containing giant clams would lead to increases in the photosynthetic rate of the symbionts (Summons et al., 1986) as well as the growth rate of the host (Hastie et al., 1988, 1992; Onate and Naguit, 1989). Moreover, symbiotic dinoflagellates isolated from giant clams absorb environmental ammonia and $\mathrm{NO}_{3}{ }^{-}$(Wilkerson and Trench, 1986). Thus, both the clam host and the symbiotic dinoflagellates are $\mathrm{N}$-deficient.

The ctenidium of $T$. squamosa displays $\mathrm{H}^{+} / \mathrm{K}^{+}\left(\mathrm{NH}_{4}{ }^{+}\right)$ATPase activity, and the ctenidial $\mathrm{NH}_{4}{ }^{+}$-activated $\mathrm{H}^{+} / \mathrm{K}^{+}$ATPase activity increases significantly after $12 \mathrm{~h}$ of light exposure (Ip et al., 2015). As $\mathrm{H}^{+} / \mathrm{K}^{+}$-ATPase is typically localized in the apical membrane of epithelial cells (Swarts et al., 2005), it can probably catalyze the active uptake of $\mathrm{K}^{+}$or $\mathrm{NH}_{4}^{+}$ from the ambient seawater in the ctenidial epithelial cells of T. squamosa (Figure 4). However, $\mathrm{H}^{+} / \mathrm{K}^{+}$-ATPase has not been cloned and characterized from T. squamosa, and the possible involvement of other ammonia transporters cannot be eliminated at present. Due to its deleterious effects (Ip and Chew, 2010), ammonia must be converted into some other compounds in the cytoplasm of the ctenidial epithelial cells. This can also maintain the favorable transmembrane $\mathrm{PNH}_{3}$ and $\left[\mathrm{NH}_{4}{ }^{+}\right]$gradients needed for the continuous absorption of exogenous ammonia. Catalyzed by GS, ammonia (as $\mathrm{NH}_{4}{ }^{+}$) can undergo ATPdependent ligation with glutamate to form glutamine (Taylor and Curthoys, 2004). In giant clams, the ctenidium displays higher GS activity than other host's organs and the isolated dinoflagellates (Rees et al., 1994; Yellowlees et al., 1994), indicating that it can play a major role in the assimilation of exogenous ammonia (Rees et al., 1994; Shepherd et al., 1999). By contrast, GS of symbiotic dinoflagellates, and not that of the host, are presumably responsible for the assimilation of exogenous ammonia in scleractinian corals (Miller and Yellowlees, 1989) and symbiotic sea anemones (Swanson and Hoegh-Guldberg, 1998).

The complete cDNA coding sequence of a host GS has been obtained from the ctenidium of T. squamosa (Hiong et al., 2017a). Its transcript level and protein abundance increase significantly in the ctenidium of individuals exposed to light for $12 \mathrm{~h}$ (Hiong et al., 2017a). GS is localized in the cytoplasm of the epithelial cells lining the tertiary water channels (Hiong et al., 2017a). Hence, these ctenidial epithelial cells probably take part in light-enhanced ammonia absorption, and their cytoplasmic GS assimilates the absorbed ammonia into glutamine, thereby maintaining a low intracellular ammonia concentration (Figure 4). The light-dependent regulation of GS expression in the ctenidium of T. squamosa (Table 1) offers a mechanistic explanation to why ctenidial GS activity is suppressed when giant clams are exposed to continuous darkness (Rees et al., 1994). It also explains why exposure to continuous darkness would lead to increased ammonia excretion (Wilkerson and Trench, 1986).

Ammonium transporters (AMTs) are known to participate in ammonia transport across the plasma membrane of prokaryotic, plant and invertebrate cells. AMT1 has been cloned and characterized from the ctenidium of T. squamosa (Boo et al., 2018). AMT1-immunofluorescence is detected mainly at the apical epithelium of ctenidial filaments, but not in those epithelial cells surrounding the tertiary water channels (Boo et al., 2018), which express GS and take part in the absorption and assimilation of exogenous ammonia (Hiong et al., 2017a). Moreover, exposure to light for 6 or $12 \mathrm{~h}$ leads to significant decreases in the transcript level and protein abundance of AMT1/AMT1 in the ctenidium (Table 1). Taken together, AMT1 is probably involved in ammonia excretion in T. squamosa, and because of that, its gene and protein expression levels need to be suppressed during illumination in order to achieve an overall light-enhanced uptake of ammonia (Figure 4).

As ammonia absorbed from the ambient seawater is assimilated directly into glutamine in the ctenidium, it is unlikely that symbiotic dinoflagellates can receive exogenous ammonia in the form of $\mathrm{NH}_{3} / \mathrm{NH}_{4}{ }^{+}$as suggested previously (Hawkins and Klumpp, 1995). Furthermore, majority of the glutamine synthesized from exogenous ammonia in the ctenidium can be utilized by the $\mathrm{N}$-deficient clam host for various anabolic purposes (Figure 4). Possibly, only a small portion of the glutamine synthesized in the ctenidium is supplied to the symbionts through the hemolymph and the intra-tubular fluid. By contrast, $\mathrm{NO}_{3}{ }^{-}$and urea absorbed from the external medium is dedicated for the $\mathrm{N}$-deficient symbionts because the host cannot metabolize them. On the other hand, endogenous ammonia produced metabolically by the host is available for the symbionts' absorption and assimilation. In fact, the success of giant clams in nutrient-poor waters in the tropics is partly attributable to the recycling of $\mathrm{N}$, especially endogenous ammonia, between the host and its symbionts. Furthermore, there are indications that $\mathrm{N}$ assimilation and recycling in the ctenidium of giant clams can involve Endozoicomonadaceae bacteria (Rossbach et al., 2019a). The symbiotic dinoflagellates of T. squamosa can generate glutamate using ammonia produced by the clam host because they possess enzymes of the glutamate synthase (GS1-GOGAT) cycle (Fam et al., 2018). The glutamate generated through GS1-GOGAT can be used for the synthesis of other amino acids through various transamination reactions 


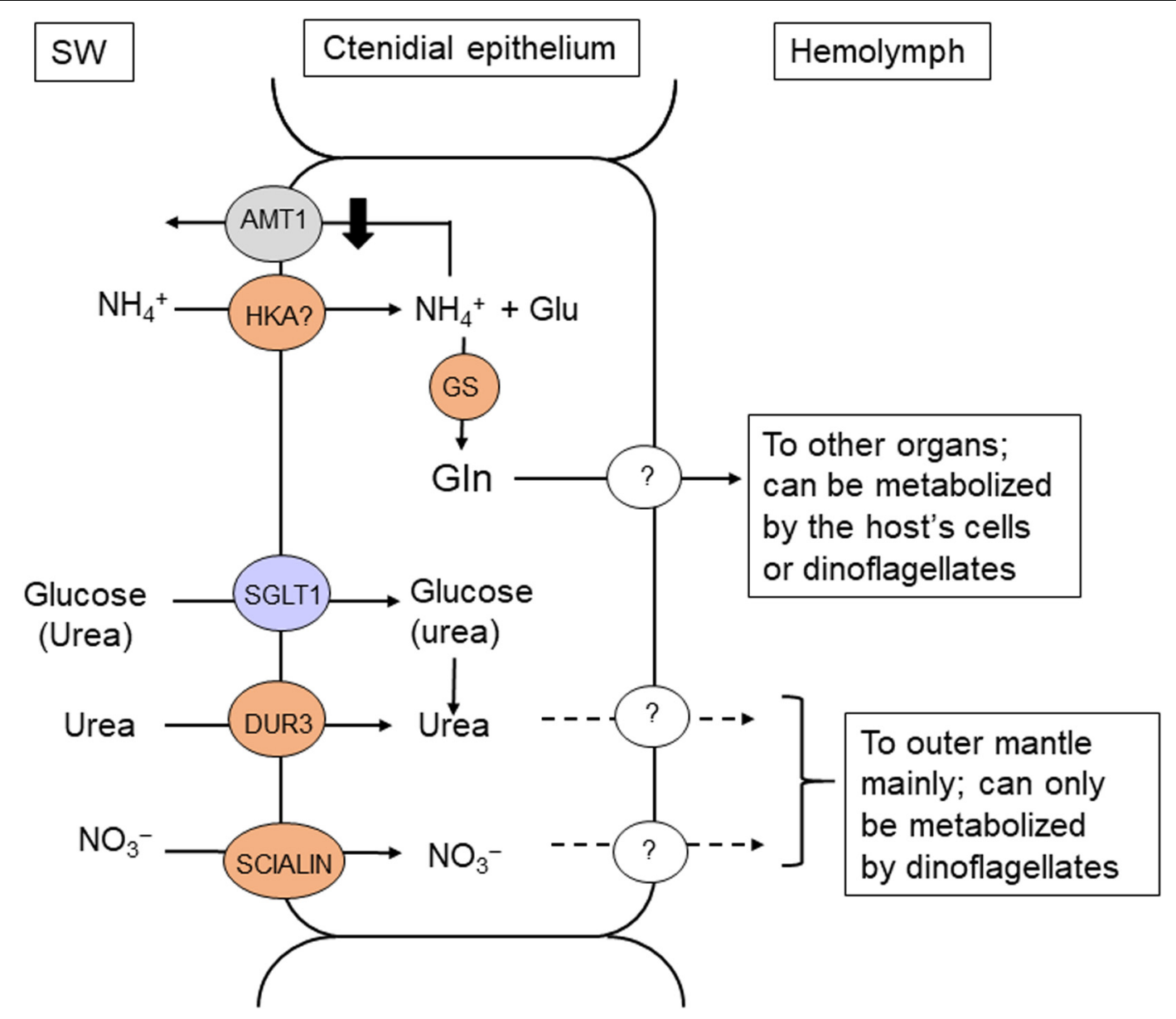

FIGURE 4 | Mechanisms of light-enhanced uptake and assimilation of ammonia, as well as absorption of urea, nitrate and glucose in the ctenidium of T. squamosa.

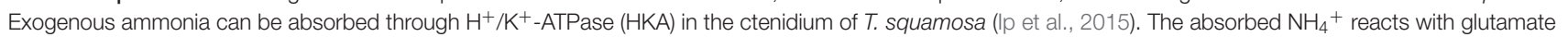
(Glu) to form glutamine (Gln), catalyzed by Glutamine Synthetase (GS), which is localized in the cytoplasm of the epithelial cells lining the tertiary water channels in the ctenidium (Hiong et al., 2017b). Ammonium transporter 1 (AMT1) can play a role in ammonia excretion in T. squamosa, and because of that, its gene and protein expression levels need to be suppressed during illumination in order to achieve the overall light-enhanced uptake of ammonia (Boo et al., 2018). As the ammonia absorbed is assimilated directly into glutamine in the ctenidium, exogenous ammonia is unlikely to be made available to the $\mathrm{N}$-deficient symbiotic dinoflagellates in the form of $\mathrm{NH}_{3} / \mathrm{NH}_{4}{ }^{+}$. Light-enhanced nitrate $\left(\mathrm{NO}_{3}{ }^{-}\right)$absorption can be facilitated by the electrogenic $\mathrm{H}^{+}: 2 \mathrm{NO}_{3}{ }^{-}$cotransporter, SIALIN, which is localized in the apical membrane of the epithelial cells located at the tips of ctenidial filaments (Ip et al., 2020a). The ctenidium can also perform light-enhanced urea absorption through the urea-proton symporter, DUR3, which has an apical localization in the epithelia of the ctenidial filaments and tertiary water channels (Chan et al., 2018). Urea can also be absorbed through $\mathrm{Na}^{+}$:Glucose Cotransporter 1 (SGLT1; purple) in the ctenidium (Chan et al., 2019). SW, seawater. ?, unidentified transporters.

(Figure 2). As transamination reactions need a supply of carbonchains, which are readily available when the symbionts conduct photosynthesis, the assimilation of ammonia by the symbionts would be greater in light than in darkness. This explains why giant clams do not excrete ammonia during illumination under normal circumstances.

In general, aquatic animals do not absorb $\mathrm{NO}_{3}{ }^{-}$from the environment, although $\mathrm{NO}_{3}^{-}$is an essential source of $\mathrm{N}$ for algae and plants. Nonetheless, T. squamosa absorbs $\mathrm{NO}_{3}{ }^{-}$from the ambient seawater at a rate faster in light $\left(0.077 \mu \mathrm{mol} \mathrm{NO}{ }^{-} \mathrm{g}^{-1} \mathrm{~h}^{-1}\right)$ than in darkness $(0.055 \mu \mathrm{mol}$ $\left.\mathrm{NO}_{3}{ }^{-} \mathrm{g}^{-1} \mathrm{~h}^{-1}\right)$. Additionally, its ctenidium strongly expresses a homolog of the electrogenic $\mathrm{H}^{+}: 2 \mathrm{NO}_{3}{ }^{-}$cotransporter, SIALIN, which participates in $\mathrm{NO}_{3}{ }^{-}$excretion in acinar cells of human salivary glands (Ip et al., 2020a). In T. squamosa, SIALIN is localized in the apical membrane of the epithelial cells located at the tips of ctenidial filaments, and it can therefore absorb exogenous $\mathrm{NO}_{3}^{-}$(Figure 4). It can facilitate lightenhanced $\mathrm{NO}_{3}{ }^{-}$absorption because its transcript level and protein abundance increase significantly in the ctenidium of T. squamosa during illumination (Table 1; Ip et al., 2020a). It has been reported that scleractinian corals can also absorb exogenous $\mathrm{NO}_{3}{ }^{-}$, but, unlike T. squamosa, the rate of $\mathrm{NO}_{3}{ }^{-}$ uptake is unaffected by light exposure (Franzisket, 1973; Grover and Maguer, 2003; Badgley et al., 2006). At present, there is no evidence of SIALIN expression in scleractinian corals.

In spite of its low concentration (0.1-2.2 $\left.\mu \mathrm{mol} \mathrm{l}^{-1}\right)$ in seawater, urea represents a significant quantity of seawater 
N (Crandall and Teece, 2012). Due to the lack of urease, animals excrete the urea produced endogenously. By contrast, T. squamosa absorbs urea from the external medium, and the rate of urea uptake in light $\left(0.045 \mu \mathrm{mol}\right.$ urea $\left.\mathrm{g}^{-1} \mathrm{~h}^{-1}\right)$ is significantly higher than that in darkness $(0.029 \mu \mathrm{mol}$ urea $\mathrm{g}^{-1} \mathrm{~h}^{-1}$; Chan et al., 2018). Because of the low [urea] in seawater, giant clams must possess some sort of active urea transporter in their ctenidium to augment urea absorption during illumination. The complete coding cDNA sequence of a homolog of the ureaproton symporter, DUR3, has been obtained from the ctenidium of T. squamosa (Chan et al., 2018). While $12 \mathrm{~h}$ of light exposure has no significant effect on the transcript level of ctenidial DUR3, the DUR3 protein abundance increases progressively in the ctenidium between hour 3 and hour $12 \mathrm{~h}$ of light exposure, and it becomes significantly greater than the control at hour 12 (Table 1; Chan et al., 2018). DUR3 has an apical localization in the epithelial cells of the ctenidial filaments and tertiary water channels (Chan et al., 2018), denoting that it can take part in light-enhanced urea absorption in T. squamosa (Figure 4).

Urea can also be absorbed through a homolog of $\mathrm{Na}^{+}$: Glucose Cotransporter 1 (SGLT1) in the ctenidium of T. squamosa (Figure 4). The complete cDNA coding sequence of SGLT1 has been cloned from the ctenidium of T. squamosa, and the ability of SGLT1 to transport urea besides glucose has been confirmed through molecular characterization (Chan et al., 2019). SGLT1 has an apical localization in the epithelium of ctenidial filaments and water channels, and exposure to light leads to a stronger apical SGLT1-immunofluorescence (Chan et al., 2019). In addition, exposure to light for $12 \mathrm{~h}$ leads to a significant increase in the protein abundance of SGLT1 in the ctenidium (Table 1). Evidently, T. squamosa can conduct lightenhanced glucose absorption, and the rate of glucose absorption is impeded by exogenous urea, confirming that SGLT1 can transport both glucose and urea as predicted by molecular characterization (Chan et al., 2019). It is possible that the aposymbiotic larvae of giant clams may depend on the absorption of exogenous glucose through ctenidial SGLT1 for survival. However, the quantity of exogenous glucose absorbed by adult giant clams is probably insignificant compared with the quantity of photosynthate donated by the symbionts during illumination. Therefore, ctenidial SGLT1 may play a more important role in light-enhanced urea uptake in adult giant clams (Figure 4).

Scleractinian corals also absorb ammonia (Muscatine and D'Elia, 1978), urea (Grover et al., 2006), and $\mathrm{NO}_{3}{ }^{-}$(Franzisket, 1973) from the ambient seawater. While the rates of ammonia and urea absorption in scleractinian corals increase during illumination, the rate of $\mathrm{NO}_{3}{ }^{-}$absorption is unaffected by light (Badgley et al., 2006). Nonetheless, it is unclear at present whether scleractinian corals express DUR3, SGLT1 and SCIALIN, and if they do, whether the expression levels of these transporters could be enhanced by light. It has been proposed that the cnidarian host can increase the recycling of its own metabolic ammonia into non-essential amino acid when photosynthate are available (Falkowski et al., 1993; Cui et al., 2019), which may serve to control the availability of ammonia to the symbionts and to regulate their population (Cui et al., 2019; Xiang et al., 2020). However, such a proposition may not be valid because the quantity of endogenous ammonia produced and recycled by the host is probably insignificant as compared with the quantities of nitrogenous compounds absorbed from the ambient seawater through light-enhanced molecular mechanisms. Importantly, the exogenous urea and $\mathrm{NO}_{3}{ }^{-}$absorbed by the host must be made available fully to the symbionts because the host cannot metabolize them.

\section{THE HOST CONDUCTS LIGHT-ENHANCED ABSORPTION OF INORGANIC PHOSPHATE $\left(\mathbf{P}_{i}\right)$}

$\mathrm{P}$ is an essential element for all living organisms. In aqueous solution, $\mathrm{P}$ is present as $\mathrm{P}_{i}$, which consists of dihydrogen phosphate $\left(\mathrm{H}_{2} \mathrm{PO}_{4}{ }^{-}\right)$, hydrogen phosphate $\left(\mathrm{HPO}_{4}{ }^{2-}\right)$, and phosphate $\left(\mathrm{PO}_{4}{ }^{3-}\right)$. At $\mathrm{pH}$ 7.2, $\mathrm{P}_{i}$ comprises a mixture of $\mathrm{HPO}_{4}{ }^{2-}$ and $\mathrm{H}_{2} \mathrm{PO}_{4}{ }^{-}$in physiological fluids. $\mathrm{P}_{i}$ is required for the syntheses of ATP, phospholipids and genetic materials (Knowles, 1980). It is also needed for intracellular signaling (Olsen et al., 2006). Symbiotic dinoflagellates are P-deficient (Jackson et al., 1989). Thus, when cultured dinoflagellates isolated from $T$. gigas are exposed to $10 \mu \mathrm{M} \mathrm{P}_{i}$, their intracellular $\left[\mathrm{P}_{i}\right]$ increases and their population grows (Belda and Yellowlees, 1995). By contrast, exposure of $T$. gigas to an elevated concentration $(10 \mu \mathrm{M})$ of $\mathrm{P}_{i}$ does not augment the $\mathrm{N}: \mathrm{P}$ ratio in its symbionts and has no effect on the symbiont population size (Belda and Yellowlees, 1995). Therefore, it has been proposed that the clam host can regulate the symbiont population by controlling the availability of $\mathrm{P}_{i}$ to them. It has been postulated that the clam host can accumulate $\mathrm{P}_{i}$ in the kidney so as to lower $\left[\mathrm{P}_{i}\right]$ in the hemolymph (Belda and Yellowlees, 1995). However, the crucial factor to be considered should be the $\left[\mathrm{P}_{i}\right]$ in the intra-tubular fluid, and not the $\left[\mathrm{P}_{i}\right]$ in the hemolymph, because symbionts are surrounded by the former instead of the latter. Logically, the concentrations of various solutes in the intratubular fluid can be regulated by the tubular epithelial cells, which undoubtedly possess relevant transporters and enzymes to fulfill the symbionts' needs. As symbionts are P-deficient, the host must provide them with $\mathrm{P}_{i}$ absorbed from the ambient seawater through the hemolymph and the intra-tubular fluid, particularly during photosynthesis.

Indeed, T. squamosa absorbs $\mathrm{P}_{i}$ faster in light than in darkness (Chan et al., 2020). As the $\left[\mathrm{P}_{i}\right]$ of $0.08-0.5 \mu \mathrm{M}$ in seawater (Rivkin and Swift, 1985; Godinot et al., 2009) is much lower than the $\left[\mathrm{P}_{i}\right]$ of $1-10 \mathrm{mM}$ in the cytoplasm of cells (Jackson and Yellowlees, 1990), T. squamosa must possess some sorts of active (or $\mathrm{Na}^{+}$-dependent) phosphate transporter to catalyze the active uptake of exogenous $\mathrm{P}_{i}$. Indeed, Chan et al. (2020) have obtained the complete coding cDNA sequence of a homolog of Sodium-dependent Phosphate Transport protein 2a (NPT2a) from the ctenidium of T. squamosa. NPT2a is expressed strongly in the ctenidium, the outer mantle and the inner mantle, but only weakly in all other organs including the kidney (Chan et al., 2020). NPT2a has an apical localization in the epithelia covering the sun-facing portion of the outer mantle, the seawaterfacing side of the inner mantle, and the ctenidial filaments. 
As these three epithelia are in direct contact with seawater, they can actively absorb $\mathrm{P}_{i}$ from the external medium through their apical NPT2a.

The gene and protein expression levels of NPT2a/NPT2a are high in the ctenidium of T. squamosa, but they are unaffected by illumination (Table 1 ) indicating that the ctenidium may not be essential to light-enhanced $\mathrm{P}_{i}$ absorption (Chan et al., 2020). As $P_{i}$ is an important but scarce nutrient in seawater, T. squamosa probably needs to maintain a certain capacity of $\mathrm{P}_{i}$ uptake through ctenidial NPT2a be it in darkness or in light. On the other hand, illumination leads to an increase in the protein abundance of NPT2a in the outer mantle denoting it as a major site of light-enhanced $\mathrm{P}_{i}$ absorption (Table 1; Chan et al., 2020). Dinoflagellates need an increased supply of $\mathrm{P}_{i}$ for the synthesis of ATP through the light-dependent reactions of photosynthesis (Stock et al., 2000). The $\mathrm{P}_{i}$ absorbed by the epithelial cells of the outer mantle can be translocated through a short distance to the photosynthesizing symbionts residing therein (Figure 1). This would spare the symbionts of the outer mantle from competing with various host's organs, particularly the kidney (Belda and Yellowlees, 1995), for the $\mathrm{P}_{i}$ circulating in the hemolymph (Chan et al., 2020).

For scleractinian corals, both the host animal and isolated dinoflagellates are known to absorb $\mathrm{P}_{i}$ from the external medium (Jackson and Yellowlees, 1990; Godinot et al., 2009). Furthermore, a loss of biomass, disruption of symbiont photosynthesis, and bleaching can occur in scleractinian corals with an undersupply of $\mathrm{P}_{i}$ (Rosset et al., 2017). $\mathrm{P}_{i}$ uptake in scleractinian corals is light-dependent (Godinot et al., 2009), and probably involves a host's $\mathrm{Na}^{+}: \mathrm{P}_{i}$ symporter because $\mathrm{P}_{i}$ uptake can be completely inhibited by omitting $\mathrm{Na}^{+}$from the external medium (Godinot et al., 2011). However, the molecular mechanism of $\mathrm{P}_{i}$ absorption in scleractinian corals has not been identified.

\section{THE INNER MANTLE PARTICIPATES IN LIGHT-ENHANCED SHELL FORMATION}

The soft tissues and organs of a giant clam are located in the mantle cavity and protected by the shell consisting of two shell-valves. Hence, the shell-valves must enlarge in order to accommodate their growth. Giant clams grow faster in light than in darkness (Lucas et al., 1989; Klumpp and Griffiths, 1994; Watanabe and Oba, 1999), which can be attributed partially to the supply of photosynthate from the symbionts during daytime. As a result, their shells must also grow faster during illumination (Rossbach et al., 2019b). Due to light-enhanced shell formation, striking diurnal variations in the ratio of strontium (Sr) to calcium (Ca) have been reported for the cross-sections of the shells of T. derasa (Sano et al., 2012).

The whitish inner mantle is responsible for shell formation. It is connected to the colorful outer mantle and in direct contact with the extrapallial fluid. During shell formation, $\mathrm{CaCO}_{3}$ is deposited from the extrapallial fluid onto the inside surface of the shell valve according to the reaction, $\mathrm{Ca}^{2+}+\mathrm{HCO}_{3}^{-}$ $\mathrm{CaCO}_{3}+\mathrm{H}^{+}$. Therefore, the supply of $\mathrm{Ca}^{2+}$ and $\mathrm{HCO}_{3}^{-}$(or
$\mathrm{C}_{i}$ ) to and the removal of $\mathrm{H}^{+}$from the extrapallial fluid must be augmented during illumination. The increases in $\left[\mathrm{Ca}^{2+}\right]$ and $\left[\mathrm{HCO}_{3}{ }^{-}\right]$in the extrapallial fluid would result in supersaturation of $\mathrm{CaCO}_{3}$, while the increased removal of $\mathrm{H}^{+}$would promote the precipitation of aragonite. Indeed, the extrapallial fluid of T. squamosa exposed to light displays a significant increase in $\mathrm{pH}$, with a concomitant decrease in the concentration of ammonia (Ip et al., 2006). Thus, it has been proposed that $\mathrm{NH}_{3}$ helps to remove the excess $\mathrm{H}^{+}$produced during shell formation by combining with it to form $\mathrm{NH}_{4}{ }^{+}$(Figure 5). $\mathrm{NH}_{4}{ }^{+}$is then transported from the extrapallial fluid into the shell-facing epithelial cells of the inner mantle through some unknown transporters (Ip et al., 2006). The $\mathrm{H}^{+}$produced during light-enhanced shell formation can also be transported from the extrapallial fluid into the inner mantle epithelial cells through Plasma Membrane $\mathrm{Ca}^{2+}$-ATPase (PMCA; Figure 5), which catalyses the exchange of $\mathrm{Ca}^{2+}$ with $\mathrm{H}^{+}$(Ip et al., 2017a). Subsequently, the excess $\mathrm{H}^{+}$ can be translocated into the hemolymph, and shuttled to the ctenidium (Figure 3) where it can be excreted through the apical NHE3 (Hiong et al., 2017b) or VHA (Ip et al., 2018) to augment $\mathrm{C}_{i}$ absorption.

The ctenidium of giant clams is an important site of $\mathrm{C}_{i}$ absorption, but it is remote from the site of shell formation (extrapallial fluid). Furthermore, to conduct light-enhanced shell formation, the inner mantle would have to compete with the photosynthesizing symbionts of the outer mantle for the $C_{i}$ absorbed through the ctenidium. This could be the reason why the seawater-facing epithelial cells of the inner mantle also have the ability to absorb $\mathrm{C}_{i}$ from the ambient seawater, whereby the absorbed $\mathrm{C}_{i}$ can be conveniently used by the nearby shellfacing epithelium for shell formation. A homolog of Carbonic Anhydrase 4 (CA4) of the host's origin has been sequenced from the whitish inner mantle of T. squamosa (Chew et al., 2019). Based on transcript levels, CA4 is the major CA expressed in the inner mantle, and the quantity of CA4 transcript in the inner mantle is higher than those in the outer mantle and the ctenidium. In the inner mantle, CA4 is localized in the apical membrane of the seawater-facing epithelial cells, but it is undetectable in the shell-facing epithelium (Chew et al., 2019). The active site of CA4 is known to be positioned extracellularly (Shah et al., 2005); hence, it is in direct contact with the ambient seawater and can catalyze the dehydration of exogenous $\mathrm{HCO}_{3}{ }^{-}$to $\mathrm{CO}_{2}$ to promote $\mathrm{CO}_{2}$ uptake (Figure 5). The protein abundance of CA4 increases significantly in the inner mantle after 6 or $12 \mathrm{~h}$ of exposure to light (Table 1), indicating that there could be an augmentation in the capacity to dehydrate $\mathrm{HCO}_{3}{ }^{-}$and promote $\mathrm{CO}_{2}$ uptake during illumination. Inside the epithelial cells, the absorbed $\mathrm{CO}_{2}$ can be hydrated back to $\mathrm{HCO}_{3}{ }^{-}$by $\mathrm{CA} 2$, because CA2 is also present in the cytoplasm of the seawaterfacing epithelial cells (Figure 5) but not the epithelial cells facing the shell (Chew et al., 2019).

In the inner mantle of T. squamosa, an apical beta NHE $(\beta \mathrm{NHE})$, which can excrete $\mathrm{H}^{+}$to promote $\mathrm{HCO}_{3}{ }^{-}$dehydration in the external medium, is also expressed in the apical membrane of the seawater-facing epithelium (Cao-Pham et al., 2019a). The apical $\beta$ NHE-immunostaining of the seawaterfacing epithelium is consistently stronger after exposure to 


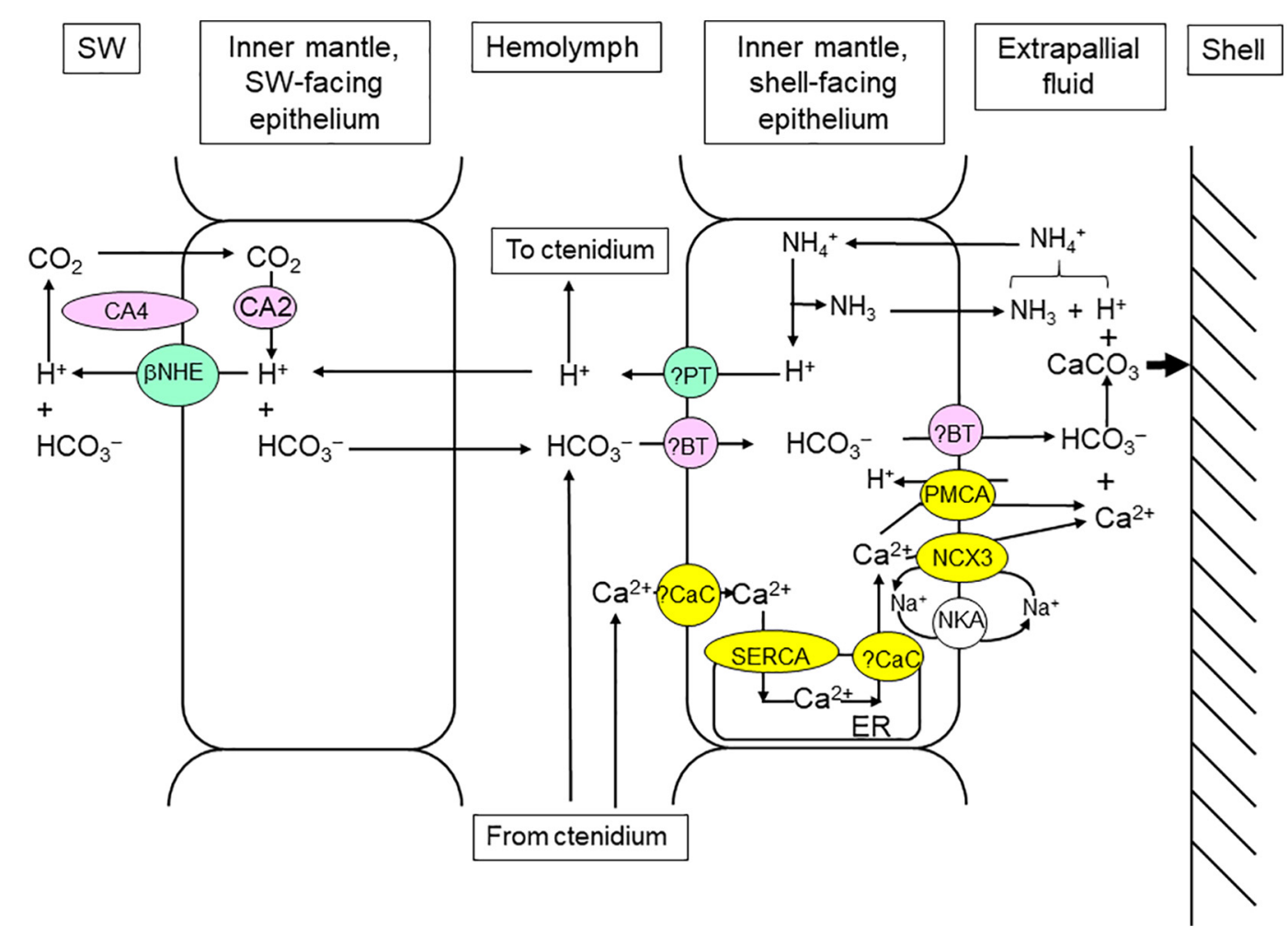

FIGURE 5 | Mechanisms of light-enhanced shell formation in the inner mantle of Tridacna squamosa. $\mathrm{CaCO}_{3}$ is deposited from the extrapallial fluid onto the inside surface of the shell valve with the production of $\mathrm{H}^{+}$during shell formation. The supply of $\mathrm{Ca}^{2+}$ and $\mathrm{HCO}_{3}{ }^{-}$(or $\mathrm{C}_{i}$ ) to and the removal of $\mathrm{H}^{+}$from the extrapallial fluid increase during illumination. $\mathrm{NH}_{3}$ may help to remove the excess $\mathrm{H}^{+}$produced during shell formation by combining with it to form $\mathrm{NH}_{4}^{+}\left(\mathrm{lp}\right.$ et al., 2006). The $\mathrm{H}^{+}$ produced can also be transported from the extrapallial fluid into the inner mantle epithelial cells through Plasma Membrane Ca ${ }^{2+}$-ATPase (PMCA; Ip et al., 2017a). Subsequently, the excess $\mathrm{H}^{+}$can be translocated to the hemolymph, followed by shuttling to the ctenidium for excretion (see Figure 2). The seawater-facing epithelium of the inner mantle also possesses Carbonic Anhydrase 4 (CA4; Chew et al., 2019) and Carbonic Anydrase 2 (CA2; Chew et al., 2019), and they operate collaboratively to assimilate $\mathrm{C}_{i}$ from the ambient seawater. An apical beta $\mathrm{Na}^{+} / \mathrm{H}^{+}$Exchanger ( $\left.\beta \mathrm{NHE}\right)$, which is expressed in the seawater-facing epithelium of the inner mantle, can excrete some of the excess $\mathrm{H}^{+}$generated (Cao-Pham et al., 2019a). The apical $\mathrm{Na}^{+} / \mathrm{Ca}^{2+}$ exchanger 3 (NCX3) in the shell-facing inner mantle epithelium can deliver $\mathrm{Ca}^{2+}$ to the extrapallial fluid at a high rate (Boo et al., 2019), while the apical PMCA can function to fine-tune cytosolic [Ca ${ }^{2+}$ ( (Ip et al., 2018). The operation of NCX3 requires the support of $\mathrm{Na}^{+} / \mathrm{K}^{+}$-ATPase (NKA; Boo et al., 2017), and the movement of $\mathrm{Ca}^{2+}$ inside the epithelial cells needs the participation of Sarcoplasmic Reticulum $\mathrm{Ca}^{2+}$-ATPase (SERCA; Chan et al., 2020). ER, endoplasmic reticulum. ?BT, unidentified Bicarbonate Transporters. ?CaC, unidentified calcium channel. ?PT, unidentified proton transporter. SW, seawater.

light for $12 \mathrm{~h}$ as compared with the control exposed to $12 \mathrm{~h}$ of darkness. Additionally, exposure to light also leads to a significant increase in the protein abundance of $\beta \mathrm{NHE}$ in the inner mantle (Table 1). Hence, the light-dependent $\beta$ NHE of the seawater-facing epithelium can probably excrete some of the excess $\mathrm{H}^{+}$generated during light-enhanced shell formation in order to reduce the impact on the $\mathrm{pH}$ of the hemolymph and other organs (Figure 5). Moreover, the excreted $\mathrm{H}^{+}$could promote the dehydration of exogenous $\mathrm{HCO}_{3}{ }^{-}$catalyzed by CA4 to augment the absorption of $\mathrm{C}_{i}$ through the seawaterfacing epithelium.

To achieve light-enhanced shell formation, the supply of $\mathrm{Ca}^{2+}$ from the shell-facing epithelial cells of the inner mantle to the extrapallial fluid must increase during illumination in order to achieve saturating $\left[\mathrm{Ca}^{2+}\right]$ and $\left[\mathrm{HCO}_{3}^{-}\right] . \mathrm{Ca}^{2+}$ can be pumped out of a cell by two transporters located in the plasma membrane, PMCA and $\mathrm{Na}^{+} / \mathrm{Ca}^{2+}$ exchange 3 (NCX3). PMCA has a high $\mathrm{Ca}^{2+}$ affinity but low $\mathrm{Ca}^{2+}$ transport capacity, whereas NCX3 has a low affinity for $\mathrm{Ca}^{2+}$ but high capacity for its transport (Brini and Carafoli, 2011). The inner mantle of T. squamosa expresses $P M C A$, the complete coding cDNA of which comprises $3597 \mathrm{bp}$, encoding a protein with 1198 amino acids of $131.9 \mathrm{kDa}$ (Ip et al., 2018). There is an apical targeting element in the deduced PMCA sequence, and its apical localization in the shell-facing epithelium of the inner mantle has been verified by immunofluorescence microcopy (Ip et al., 2018). As PMCA pumps $\mathrm{Ca}^{2+}$ out of the cell in exchange for $\mathrm{H}^{+}$with a $1: 1$ stoichiometry (Salvador et al., 1998), it can actively secrete $\mathrm{Ca}^{2+}$ from the shell-facing epithelium to, and absorb $\mathrm{H}^{+}$from, the extrapallial fluid (Figure 5). Exposure to light for $12 \mathrm{~h}$ results in a significant increase in the apical PMCA-immunofluorescence of the shell-facing epithelium (Ip et al., 2018). The transcript and protein levels of $P M C A / P M C A$ also increase significantly in the inner mantle after 6 or $12 \mathrm{~h}$ of light exposure (Table 1), indicating that the expression levels of PMCA/PMCA can be enhanced by light. 
In addition, the cDNA coding sequence of a homolog of NCX3 has been obtained from the inner mantle of T. squamosa (Boo et al., 2019). NCXs are known to participate in the calcification processes of invertebrate calcifying cells and mammalian osteoblasts. Indeed, NCX3 can participate in light-enhanced calcification in T. squamosa due to several reasons. Firstly, NCX3 is immunolocalized in the apical epithelium of the shellfacing inner mantle. Secondly, light exposure leads to stronger NCX3-immunofluorescence in the shell-facing inner mantle as compared with the control kept in darkness for $12 \mathrm{~h}$. Thirdly, light exposure results in increases in the transcript level and protein abundance of $N C X 3 / \mathrm{NCX} 3$ as compared with the control (Table 1). Thus, there is probably an increase in the capacity of NCX3 to pump $\mathrm{Ca}^{2+}$ out of the shell-facing epithelial cells into the extrapallial fluid in exchange for $\mathrm{Na}^{+}$(Figure 5). The increased movement of $\mathrm{Na}^{+}$down the transmembrane $\mathrm{Na}^{+}$ electrochemical gradient into the cell can disrupt the intracellular $\mathrm{Na}^{+}$homeostasis, and the excess $\mathrm{Na}^{+}$entering the cell must therefore be pumped out. Indeed, there is an increase in the capacity of NKA to actively extrude $\mathrm{Na}^{+}$out of the cell. The cDNA coding sequence of NKA $\alpha$-subunit $(N K A \alpha)$ has been obtained from the inner mantle of T. squamosa (Boo et al., 2017). NKA $\alpha$ has a basolateral localization along the shell-facing epithelium of the inner mantle, and there is a significantly stronger basolateral NKA $\alpha$-immunofluorescence at the shellfacing epithelium of individuals exposed to light for $12 \mathrm{~h}$ than that of the control (Boo et al., 2017). In addition, illumination leads to a significant increase in the protein abundance of NKA $\alpha$ in the inner mantle (Table 1). Taken together, the increased expression level of NKA in the shell-facing epithelial cells of the inner mantle of individuals exposed to light is needed to cope with the rise in $\mathrm{Na}^{+}$influx caused by the increase in operation of NCX3 to support light-enhanced shell formation (Figure 5).

As light-enhanced shell formation requires an increase in the transport of $\mathrm{Ca}^{2+}$ from the shell-facing epithelial cells of the inner mantle into the extrapallial fluid, the uptake of $\mathrm{Ca}^{2+}$ from the hemolymph by these epithelial cells must be augmented during illumination. At present, the transporters/channels involved in the absorption of $\mathrm{Ca}^{2+}$ into these epithelial cells have not been identified. Nonetheless, it is important to understand how the absorbed $\mathrm{Ca}^{2+}$ can move across the cytoplasm, from the basolateral membrane to the apical membrane, so that it can be accessed by the apical PMCA and NCX3 but without increasing the cytosolic $\left[\mathrm{Ca}^{2+}\right]$ and perturbing $\mathrm{Ca}^{2+}$ homeostasis. It has been established that sarcoplasmic/endoplasmic reticulum $\mathrm{Ca}^{2+}$-ATPase (SERCA) pumps $\mathrm{Ca}^{2+}$ into the sarcoplasmic/endoplasmic reticulum and Golgi apparatus in order to maintain low intracellular $\left[\mathrm{Ca}^{2+}\right]$. As expected, the inner mantle of $T$. squamosa expresses a homolog of SERCA, and the protein abundance of SERCA increases significantly after $6 \mathrm{~h}$ of exposure to light (Table 1; Chan et al., 2020). Presumably, this would avert a possible surge in the cytosolic $\left[\mathrm{Ca}^{2+}\right.$ ] in the shell-facing epithelial cells of the inner mantle during light-enhanced shell formation by increasing the capacity of pumping $\mathrm{Ca}^{2+}$ into the endoplasmic reticulum (Figure 5).
Taken together, the mechanisms that directly contribute to light-enhanced shell formation in T. squamosa are the host's $\mathrm{Ca}^{2+}$ transporters, whereby the expression of the transporters can be enhanced by illumination (Figure 5). They offer a novel explanation for light-enhanced shell formation in giant clams, which is directly related to light-enhanced mechanisms of the host and unrelated to the removal of $\mathrm{CO}_{2}$ by the photosynthesizing symbionts as proposed by Goreau (1959) for light-enhanced skeleton formation in scleractinian corals. They also offer a mechanistic explanation of the variability of $\mathrm{Sr} / \mathrm{Ca}$ in the shells of giant clams as reported by Sano et al. (2012). If the dehydration of $\mathrm{HCO}_{3}{ }^{-}$to $\mathrm{CO}_{2}$ indeed occurs in the extrapallial fluid, it would reduce $\left[\mathrm{HCO}_{3}{ }^{-}\right]$therein and impede shell formation by lowering the solubility product of $\left[\mathrm{Ca}^{2+}\right]$ and $\left[\mathrm{HCO}_{3}{ }^{-}\right]$. Nonetheless, light-enhanced shell formation in giant clams is related indirectly to the release of photosynthate and $\mathrm{O}_{2}$ from symbiotic dinoflagellates. This is because the operations of the host's PMCA, SERCA, and NKA are driven by energy released through ATP hydrolysis, and the rate of ATP synthesis through aerobic energy metabolism and oxidative phosphorylation in the host can be augmented by the supply of photosynthate and $\mathrm{O}_{2}$ from its symbionts.

During shell formation, $\mathrm{CaCO}_{3}$ is precipitated from the extrapallial fluid onto a proteinaceous matrix lining the inner surface of the shell-valve (Wilbur and Watabe, 1963; Wheeler and Sikes, 1984). The inner mantle lacks iridocytes and direct light exposure, but it contains symbiotic dinoflagellates concentrated in a specific area near the valve hinge (Poo et al., 2020). The transcript level and protein abundance of Zoox-URE/ZooxZURE in the inner mantle are upregulated during illumination (Table 1; Ip et al., 2020b). Probably, this can increase the release of urea-N for amino acid production in the symbionts, and the amino acids donated to the inner mantle cells can augment the synthesis of proteinaceous matrix for shell formation (Wilbur and Saleuddin, 1983). As symbionts in the inner mantle have low phototrophic potential (Poo et al., 2020), they would probably need to absorb some of the photosynthate (carbon-chains), which are present in the intra-tubular fluid of the tubular system and originated from the photosynthesizing symbionts of the outer mantle, for amino acid synthesis (Figure 2).

Unlike shell formation in giant clams, the formation of skeleton in scleractinian corals involves the deposition of aragonite crystals in the subcalicoblastic fluid underneath the calicoblastic cells. It has been proposed that these cells can absorb $\mathrm{Ca}^{2+}$ passively through some sort of $\mathrm{Ca}^{2+}$ channels (Zoccola et al., 1999), and the absorbed $\mathrm{Ca}^{2+}$ can be actively transported by PMCA (Cohen and McConnaughey, 2003; Allemand et al., 2004) or NCX (Marshall, 1996; Davy et al., 2012) across the apical membrane into the subcalicoblastic fluid. However, in calicoblastic cells, PMCA (Barott et al., 2015) and NCX (Barron et al., 2018) are localized in the cytoplasm and intracellular vesicles, respectively, and not in the apical membrane. Therefore, PMCA and NCX apparently participate in an intracellular calcification process that involves the formation of amorphous $\mathrm{CaCO}_{3}$ in the cytoplasm of scleractinian corals, (Mass et al., 2017). Skeleton formation in scleractinian corals probably involves the secretion of amorphous $\mathrm{CaCO}_{3}$, together with 
$\mathrm{HCO}_{3}{ }^{-}$and several other proteins, including coral acidic rich proteins, into the subcalicoblastic fluid (Von Euw et al., 2017). Overall, there are major differences between the mechanisms of light-enhanced skeleton formation in scleractinian corals and light-enhanced shell formation in giant clams. Notably, it remains unclear at present whether scleractinian corals would upregulate the gene and protein expression levels of PMCA, NCX, and SERCA in calicoblastic cells during illumination as in the case of giant clams.

\section{LIGHT-ENHANCED SHELL FORMATION REQUIRES AN INCREASED SUPPLY OF $\mathrm{Ca}^{2+}$ THAT IS ABSORBED THROUGH THE CTENIDIUM}

Light-enhanced shell formation occurs in the extrapallial fluid, and it necessitates increases in the uptake of $\mathrm{Ca}^{2+}$ from the ambient seawater and the supply of $\mathrm{Ca}^{2+}$ through the hemolymph to the cite of calcification during illumination. Intracellular $\left[\mathrm{Ca}^{2+}\right]$ regulates many physiological events, and the function of voltage-gated $\mathrm{Ca}^{2+}$ channels (VGCCs) is to transduce alterations in electrical potential across plasma membrane into variations in intracellular $\left[\mathrm{Ca}^{2+}\right]$ (Catterall, 2011). VGCCs can also be involved in calcification in marine invertebrates like echinoids (Dubois and Chen, 1989) and scleractinian corals (Allemand and Grillo, 1992), but it is not known to take part in the absorption of exgoenous $\mathrm{Ca}^{2+}$. In the case of T. squamosa, the complete coding cDNA sequence of a homolog of Voltage-gated Calcium Channel subunit $\alpha 1$ (CACNA1), which is the pore-forming subunit of VGCCs, has been obtained from the ctenidium (Cao-Pham et al., 2019b). The deduced amino acid sequence has been characterized as the $\alpha 1 \mathrm{D}$ subunit of L-type VGCC, which is one of the several types of high voltage activated channel. CACNA1 is immunolocalized in the apical membrane of epithelial cells that cover the ctenidial filaments facing seawater, and also in some of the epithelial cells surrounding the tertiary water channels. Thus, judging by its pore-forming subunit, L-type VGCC is well-positioned to absorb exogenous $\mathrm{Ca}^{2+}$ in the ctenidium of T. squamosa. Exposure to $12 \mathrm{~h}$ of light leads to an increase in the quantity of immunolabelled epithelial cells in the ctenidial filaments and tertiary water channels, and the immunofluorescence is stronger than the control. Light exposure also leads to significantly higher protein abundance of CACNA1 in the ctenidium as compared with the control (Table 1). More pore-forming CACNA1 in the seawater-facing apical membrane would imply a greater potential for the uptake of exogenous $\mathrm{Ca}^{2+}$ into the ctenidial epithelial cells. Hence, L-type VGCC can probably conduct a light-enhanced influx of $\mathrm{Ca}^{2+}$ from the ambient seawater into the ctenidium of T. squamosa (Figure 3). How the $\mathrm{Ca}^{2+}$ exit the ctenidial epithelial cell against the electrochemical potential gradient of $\mathrm{Ca}^{2+}$ across the basolateral membrane is uncertain at present. Future studies should consider the possible involvement of NCX, which can utilize the $\mathrm{Na}^{+}$gradient generated by the basolateral NKA to pump $\mathrm{Ca}^{2+}$ against its concentration gradient (Figure 3). The absorbed $\mathrm{Ca}^{2+}$ can be shuttled through the hemolymph to the inner mantle to support light-enhanced shell formation (Figure 5).

The ctenidium also expresses SERCA, and the epithelial cells of ctenidial filaments display non-uniform SERCAimmunolabeling in the cytoplasm (Chan et al., 2020). In addition, the protein abundance of SERCA increases significantly in the ctenidium of T. squamosa after $12 \mathrm{~h}$ of light exposure (Table 1), which would increase the capacity for pumping $\mathrm{Ca}^{2+}$ into the endoplasmic reticulum to maintain a low cytosolic $\left[\mathrm{Ca}^{2+}\right]$ in epithelial cells of the ctenidial filaments (Figure 3). Taken together, it can be concluded that light-enhanced $\mathrm{Ca}^{2+}$ uptake of $T$. squamosa is attributable primarily to the direct responses of the host's transporters in the ctenidium to light, which align well with light-enhanced mechanisms of shell formation in the inner mantle. At present, how $\mathrm{Ca}^{2+}$ can be actively transported from the ctenidial epithelial cells to the hemolymph remains unknown.

In scleractinian corals, the seawater-facing plasma membranes of calicoblastic cells are presumably involved in absorbing $\mathrm{Ca}^{2+}$ through an energy-independent process. The absorbed $\mathrm{Ca}^{2+}$ is translocated intracellularly to the other side of the cell, followed by active transport through the plasma membrane against its electrochemical gradient via some kind of energy-dependent mechanism (Berridge and Oschman, 1972). It has been reported that the L-type $\mathrm{Ca}^{2+}$ channel inhibitors, phenylalkylamine and dihydropyridine can suppress calcification in corals (Marshall, 1996; Tambuttei et al., 1996). Indeed, the calicoblastic ectoderm of corals also expresses a homolog of CACNA1 (Zoccola et al., 1999), indicating that VGCC may take part in skeleton formation in scleractinian corals by transporting $\mathrm{Ca}^{2+}$ into the subcalicoblastic fluid underlying the calicoblastic epithelium. However, as the subcalicoblastic fluid contains high $\left[\mathrm{Ca}^{2+}\right]$ to augment the deposition of $\mathrm{CaCO}_{3}$, how VGCC of the calicoblastic epithelium can transport $\mathrm{Ca}^{2+}$ outward against its electrochemical gradient remains unresolved.

\section{THE IMPORTANCE OF UNDERSTANDING LIGHT-ENHANCED PHENOMENA IN GIANT CLAMS}

At present, the existence of coral reefs is being threatened by climate change, coastal pollution, and habitat loss related to anthropogenic activities. Symbiotic reef organisms can undergo a stress response called 'bleaching', particularly when confronted with high temperatures and high irradiance. During bleaching, the host would lose symbiotic dinoflagellates, and its symbionts may have less photosynthetic pigments (Glynn and D'Croz, 1990; Lesser et al., 1990). Notably, giant clams harbor large quantities of symbionts (Griffiths and Klumpp, 1996), which can serve as reservoirs of symbiotic dinoflagellates in the reef ecosystem. While scleractinian corals expel degraded dinoflagellates (Fujise et al., 2014), those expelled by giant clams are intact, viable and competently phototrophic (Morishima et al., 2019). Importantly, healthy dinoflagellates expelled by giant clams can repopulate 
bleached Symbiodiniaceae-bearing hosts (Morishima et al., 2019) including scleractinian corals (Umeki et al., 2020). However, as a member of the reef ecosystem, the survival of giant clams is also affected negatively by various anthropogenic activities and global warming (Van Wynsberge et al., 2016; Neo et al., 2017). Results obtained from laboratory experiments indicate that the growth of giant clam shells could be impeded by high $\mathrm{PCO}_{2}$ in seawater (Watson et al., 2012; Watson, 2015). Currently, some species of giant clams are regarded as critically endangered or vulnerable. Therefore, it is crucial to gain a deep understanding of the mechanisms of light-enhanced physiological processes, including light-enhanced shell formation, in giant clams. Such an understanding may provide cues for conservation strategies, which can be used to protect giant clams from the negative impacts of climate change.

\section{PERSPECTIVE}

Two separate studies have demonstrated that the diel changes in expression levels of MnSOD (Hiong et al., 2018) and NCX3 (Boo et al., 2018) in T. squamosa are unrelated to the circadian rhythm. Apparently, T. squamosa has acquired a general signaling mechanism to coordinate the gene and protein expression levels of a variety of enzymes and transporters in multiple organs in relation to various diurnally lightdependent physiological processes (Table 1). This is evidently a result of the mutualistic relationship between the symbiotic dinoflagellates and the clam host, whereby the host needs to acquire light-responsive signaling mechanisms in order to support the symbionts' light-induced activities. Therefore, future studies should aim to elucidate these light-responsive signaling mechanisms in tissues and organs of the host. As energy is needed to drive transcription and translation processes, the diel cycle of changes in gene and protein expressions appear to be energetically uneconomical for the host. Nevertheless, giant clam-dinoflagellate associations are phototrophic, and the host can receive a potentially unlimited supply of photosynthate from its symbionts. Hence, unlike nonphotosymbiotic animals, giant clams can afford energetically to

\section{REFERENCES}

Allemand, D., Ferrier-Pagès, C., Furla, P., Houlbrèque, F., Puverel, S., Reynaud, S., et al. (2004). Biomineralisation in reef-building corals: from molecular mechanisms to environmental control. Comptes Rendus Pale 3, 453-467. doi: 10.1016/j.crpv.2004.07.011

Allemand, D., and Grillo, M. C. (1992). Biocalcification mechanism in gorgonians: $45 \mathrm{Ca}$ uptake and deposition by the mediterranean red coral Corallium rubrum. J. Exp. Zool. 262, 237-246. doi: 10.1002/jez. 1402620302

Al-Moghrabi, S., Allemand, D., and Couret, J. M. (1995). Fatty acid of the scleractinian coral Galaxea fascicularis: effect of light and feeding. J. Comp. Physiol. B 165, 183-192.

Andréfouët, S., Van Wynsberge, S., Fauvelot, C., Bruckner, A. W., and Remoissenet, G. (2014). Significance of new records of Tridacna squamosa Lamarck, 1819, in the Tuamotu and Gambier Archipelagos (French Polynesia). Molluscan Res. 34, 277-284. doi: 10.1080/13235818.2014.940662 conduct light-dependent diurnal changes in transcription and translation activities.

Future studies should also aim to examine the regulatory mechanisms involved in the turnover process and the half-life of these gene transcripts and proteins, because diurnal changes imply rapid turnover and short half-life. As all these hostmediated light-enhanced processes are fundamentally related to the photosynthesis of its symbionts residing in the outer mantle, it is essential to examine the translocation of substances, and perhaps even signaling molecules, between these two mutualistic partners. For giant clams, the epithelium of the tubular system may hold the secrets to understand the collaboration between the two mutualistic partners. At present, no information is available on how the tubular epithelium of the host can maintain high $\mathrm{PCO}_{2}$ in, and increase the supplies of ammonia, $\mathrm{NO}_{3}{ }^{-}$, urea and phosphate to, the intra-tubular fluid during illumination in support of photosynthesis in the symbionts. Moreover, nothing is known about how photosynthate donated by the symbionts are translocated through this tubular epithelium to the hemolymph. Hence, future studies should focus on elucidating the molecular mechanisms present in the apical and basolateral membranes of the tubular epithelium, which are involved in driving the unidirectional fluxes of substances between the hemolymph and the intra-tubular fluid in intact giant clamdinoflagellate associations.

\section{AUTHOR CONTRIBUTIONS}

Both authors listed have made a substantial, direct and intellectual contribution to the work, and approved it for publication.

\section{FUNDING}

This study was supported by the Singapore Ministry of Education through grants (R-154-000-A37-114 and R-154-000-B69-114) to YI and by National Institute of Education Academic Research fund through a grant (RI3/19CSF) to SC.

Anthony, K. R. N., and Fabricius, K. E. (2000). Shifting roles of heterotrophy and autotrophy in coral energetics under varying turbidity. J. Exp. Mar. Biol Ecol. 252, 221-253. doi: 10.1016/s0022-0981(00)00237-9

Aranda, M., Li, Y., Liew, Y. J., Baumgarten, S., Simakov, O., Wilson, M. C., et al. (2016). Genomes of coral dinoflagellate symbionts highlight evolutionary adaptations conducive to a symbiotic lifestyle. Sci. Rep. 6:39734. doi: 10.1038/ srep39734

Badgley, B. D., Lipschultz, F., and Sebens, K. P. (2006). Nitrate uptake by the reef coral Diploria strigosa: effects of concentration, water flow, and irradiance. Mar. Biol. 149, 327-338. doi: 10.1007/s00227-005-0180-5

Bandyopadhyay, U., Das, D., and Banerjee, R. K. (1999). Reactive oxygen species: oxidative damage and pathogenesis. Curr. Sci. 77, 658-666.

Barott, K. L., Perez, S. O., Linsmayer, L. B., and Tresguerres, M. (2015). Differential localization of ion transporters suggests distinct cellular mechanisms for calcification and photosynthesis between two coral species. Am. J. Physiol. Regul. Integr. Comp. Physiol. 309, R235-R246. 
Barron, M. E., Thies, A. B., Espinoza, J. A., Barott, K. L., Hamdoun, A., and Tresguerres, M. (2018). A vesicular $\mathrm{Na}^{+} / \mathrm{Ca}^{2+}$ exchanger in coral calcifying cells. PLoS One 13:e0205367. doi: 10.1371/journal.pone.0205367

Bayer, T., Aranda, M., Sunagawa, S., Yum, L. K., DeSalvo, M. K., Lindquist, E., et al. (2012). Symbiodinium transcriptomes: genome insights into the dinoflagellate symbionts of reef-building corals. PLoS One 7:e35269. doi: 10.1371/journal. pone.0035269

Belda, C. A., and Yellowlees, D. (1995). Phosphate acquisition in the giant clamzooxanthellae symbiosis. Mar. Biol. 124, 261-266. doi: 10.1007/bf00347130

Belda-Baillie, C. A., Sison, M., Silvestre, V., Villamor, K., Monje, V., Gomez, E. D., et al. (1999). Evidence for changing symbiotic algae in juvenile tridacnids. J. Exp. Mar. Biol. Ecol. 241, 207-221. doi: 10.1016/s0022-0981(99)00079-9

Berridge, M. J., and Oschman, J. L. (1972). Transporting Epithelia. London: Academic Press.

Blasing, O. E., Gibon, Y., Gunther, M., Hohne, M., Morcuende, R., Osuna, D., et al. (2005). Sugars and circadian regulation make major contributions to the global regulation of diurnal gene expression in Arabidopsis. Plant Cell 17, 3257-3281. doi: 10.1105/tpc. 105.035261

Boo, M. V., Hiong, K. C., Choo, C. Y. L., Cao-Pham, A. H., Wong, W. P., Chew, S. F., et al. (2017). The inner mantle of the giant clam, Tridacna squamosa, expresses a basolateral $\mathrm{Na}^{+} / \mathrm{K}^{+}$-ATPase $\alpha$-subunit, which displays light-dependent gene and protein expression along the shell-facing epithelium. PLoS One 12:e0186865. doi: 10.1371/journal.pone.0186865

Boo, M. V., Hiong, K. C., Goh, E. J. K., Choo, C. Y. L., Wong, W. P., Chew, S. F., et al. (2018). The ctenidium of the giant clam Tridacna squamosa expresses an ammonium transporter 1 that displays light-suppressed gene and protein expression and may be involved in ammonia excretion. J. Comp. Physiol. B 188, 765-777. doi: 10.1007/s00360-018-1161-6

Boo, M. V., Hiong, K. C., Wong, W. P., Chew, S. F., and Ip, Y. K. (2019). Shell formation in the giant clam, Tridacna squamosa, may involve an apical $\mathrm{Na}^{+} / \mathrm{Ca}^{2+}$ Exchanger 3 homolog in the shell-facing epithelium of the whitish inner mantle, which displays light-enhanced gene and protein expression. Coral Reefs 38, 1173-1186. doi: 10.1007/s00338-019-01848-y

Brini, M., and Carafoli, E. (2011). The plasma membrane $\mathrm{Ca}^{2+}$ ATPase and the plasma membrane sodium calcium exchanger cooperate in the regulation of cell calcium. Cold Spring Harb. Perspect. Biol. 3:a004168. doi: 10.1101/cshperspect. a004168

Campbell, J. W. (1991). “'Excretory nitrogen metabolism,", in Environmental and Metabolic Animal Physiology. Comparative Animal Physiology, ed. C. L. Prosser (New York, NY: Wiley-Interscience), 277-324.

Cao-Pham, A. H., Hiong, K. C., Boo, M. V., Choo, C. Y. L., Pang, C. Z., Wong, W. P., et al. (2019a). Molecular characterization cellular localization and light-enhanced expression of Beta- $\mathrm{Na}^{+} / \mathrm{H}^{+}$Exchanger-like in the whitish inner mantle of the giant clam Tridacna squamosa denote its role in lightenhanced shell formation. Gene 695, 101-112. doi: 10.1016/j.gene.2019.02. 009

Cao-Pham, A. H., Hiong, K. C., Boo, M. V., Choo, C. Y. L., Wong, W. P., Chew, S. F., et al. (2019b). Calcium absorption in the fluted giant clam, Tridacna squamosa, may involve a homolog of voltage-gated calcium channel subunit $\alpha 1$ that has an apical localization and displays light-enhanced protein expression in the ctenidium. J. Comp. Physiol. B 189, 693-706. doi: 10.1007/s00360-01901238-4

Catterall, W. A. (2011). Voltage-gated calcium channels. Cold Spring Harb. Perspect. Biol. 3, a00394. doi: 10.1101/cshperspect.a003947

Chan, C. Y. L., Hiong, K. C., Boo, M. V., Choo, C. Y. L., Wong, W. P., Chew, S. F., et al. (2018). Light exposure enhances urea absorption in the fluted giant clam Tridacna squamosa and up-regulates the protein abundance of a lightdependent urea active transporter DUR3-like in its ctenidium. J. Exp. Biol. 221:jeb176313. doi: 10.1242/jeb.176313

Chan, C. Y. L., Hiong, K. C., Choo, C. Y. L., Boo, M. V., Wong, W. P., Chew, S. F., et al. (2019). Increased apical sodium-dependent glucose transporter abundance in the ctenidium of the giant clam Tridacna squamosa upon illumination. J. Exp. Biol. 222:jeb195644. doi: 10.1242/jeb.195644

Chan, C. Y. L., Hiong, K. C., Choo, C. Y. L., Boo, M. V., Wong, W. P., Chew, S. F., et al. (2020). Light-enhanced phosphate absorption in the fluted giant clam, Tridacna squamosa, entails an increase in the expression of sodium-dependent phosphate transporter 2a in its colorful outer mantle. Coral Reefs 39, 1055-1070. doi: $10.1007 / \mathrm{s} 00338-020-01930-\mathrm{w}$
Chan, J. W. J., Boo, M. V., Wong, W. P., Chew, S. F., and Ip, Y. K. (2020). Illumination enhances the protein abundance of sarcoplasmic reticulum $\mathrm{Ca}^{2+}$. ATPases-like transporter in the ctenidium and whitish inner mantle of the giant clam, Tridacna squamosa, to augment exogenous $\mathrm{Ca}^{2+}$ uptake and shell formation, respectively. Comp. Biochem. Physiol. A 251:110811. doi: 10.1016/j. cbpa.2020.110811

Chew, S. F., and Ip, Y. K. (2014). Excretory nitrogen metabolism and defense against ammonia toxicity in air-breathing fishes. J. Fish Biol. 84, 603-638. doi: $10.1111 / \mathrm{jfb} .12279$

Chew, S. F., Koh, C. Z. Y., Hiong, K. C., Boo, M. V., Wong, W. P., et al. (2020). The fluted giant clam (Tridacna squamosa) increases the protein abundance of the host's copper-zinc superoxide dismutase in the colorful outer mantle, but not the whitish inner mantle, during light exposure. Comp. Biochem. Physiol. A 250:110791. doi: 10.1016/j.cbpa.2020.110791

Chew, S. F., Koh, C. Z. Y., Hiong, K. C., Choo, C. Y. L., Wong, W. P., Neo, M. L., et al. (2019). Light-enhanced expression of carbonic anhydrase 4-like supports shell formation in the fluted giant clam Tridacna squamosa. Gene 683, 101-112. doi: 10.1016/j.gene.2018.10.023

Clayton, W. S. Jr., and Lasker, K. E. (1984). Host feeding regime and zooxanthellae photosynthesis in the anemone, Aiptasia pallida (Verrill). Biol. Bull. 16, 590600. doi: $10.2307 / 1541412$

Cohen, A. L., and McConnaughey, T. A. (2003). Geochemical perspectives on coral mineralization. Rev. Min. Geochem. 54, 151-187. doi: 10.1515/9781501509346011

Cotter, K., Stransky, L., McGuire, C., and Forgac, M. (2015). Recent insights into the structure, regulation, and function of the V-ATPases. Trends Biochem. Sci. 40, 611-622. doi: 10.1016/j.tibs.2015.08.005

Crandall, J. B., and Teece, M. A. (2012). Urea is a dynamic pool of bioavailable nitrogen in coral reefs. Coral Reefs 31, 207-214. doi: 10.1007/s00338-0110836-1

Cui, G., Liew, Y. J., Li, Y., Kharbatia, N., Zahran, N. I., Emwas, A.-H., et al. (2019). Host-dependent nitrogen recycling as a mechanism of symbiont control in Aiptasia. PLoS Genet. 15:e1008189. doi: 10.1371/journal.pgen.1008189

Davy, S. K., Allemand, D., and Weis, V. M. (2012). Cell biology of cnidariandinoflagellate symbiosis. Microbiol. Mol. Biol. Rev. 76, 229-261. doi: 10.1128/ MMBR.05014-11

de Goeij, J. M., Van Oevelen, D., Vermeij, M. J., Osinga, R., Middelburg, J. J., de Goeij, et al. (2013). Surviving in a marine desert: the sponge loop retains resources within coral reefs. Science 342, 108-110. doi: 10.1126/science. 1241981

DeBoer, T. S., Baker, A. C., Erdmann, M. V., Jones, A. P. R., and Barber, P. H. (2012). Patterns of Symbiodinium distribution in three giant clam species across the biodiverse Bird's Head region of Indonesia. Mar. Ecol. Prog. Ser. 444, 117-132. doi: 10.3354/meps09413

Dhup, S., Kannan, D. C., and Dhawan, V. (2016). Understanding urea assimilation and its effect on lipid production and fatty acid composition of Scenedesmus sp. SOJ Biochem. 2:7. doi: 10.15226/2376-4589/2/1/00112

Dubois, P., and Chen, C. P. (1989). Calcification in echinoderms. Echinoderm. Stud. 3, 109-178

Falkowski, P. G., Dubinsky, Z., Muscatine, L., and McCloskey, L. (1993). Population control in symbiotic corals. BioScience 43, 606-611. doi: 10.2307/ 1312147

Fam, R. R., Hiong, K. C., Choo, C. Y., Wong, W. P., Chew, S. F., and Ip, Y. K. (2018). Molecular characterization of a novel algal glutamine synthetase (GS) and an algal glutamate synthase (GOGAT) from the colorful outer mantle of the giant clam, Tridacna squamosa, and the putative GS-GOGAT cycle in its symbiotic zooxanthellae. Gene 656, 40-52. doi: 10.1016/j.gene.2018.02.062

Ferrier-Pagès, S. C., Witting, J., Tambutte, E., and Sebens, K. P. (2003). Effect of natural zooplankton feeding on the tissue and skeletal growth of the scleractinian coral Stylophora pistillata. Coral Reefs 22, 229-240. doi: 10.1007/ s00338-003-0312-7

Fisher, C. R., Fitt, W. K., and Trench, R. K. (1985). Photosynthesis and respiration in Tridacna gigas as a function of irradiance and size. Biol. Bull. 169, 230-224. doi: $10.2307 / 1541400$

Fitt, W. K., Fisher, C. R., and Trench, R. K. (1986). Contribution of the symbiotic dinoflagellate Symbiodinium microadriaticum to the nutrition, growth and survival of larval and juvenile tridacnid clams. Aquaculture 55, 5-22. doi: 10.1016/0044-8486(86)90051-7 
Fitt, W. K., Rees, T. A. V., Braley, R. D., Lucas, J. S., and Yellowlees, D. (1993). Nitrogen flux in giant clams: size-dependency and relationship to zooxanthellae density and clam biomass in the uptake of dissolved inorganic nitrogen. Mar. Biol. 117, 381-386.

Fitt, W. K., and Trench, R. K. (1981). Spawning, development and acquisition of zooxanthellae by Tridacna squamosa (Mollusca, Bivalvia). Biol. Bull. 161, 213-235. doi: 10.2307/1540800

Fliegel, L., and Dibrov, P. (1996). "Biochemistry and molecular biology of the $\mathrm{Na}^{+} / \mathrm{H}^{+}$exchanger: an overview," in The $\mathrm{Na}^{+} / \mathrm{H}^{+}$Exchanger, ed. L. Fliegel (Austin, TX: R.G. Landes Company), 1-20.

Foyer, C. H. (2018). Reactive oxygen species, oxidative signaling and the regulation of photosynthesis. Environ. Exp. Bot. 154, 134-142. doi: 10.1016/j.envexpbot. 2018.05.003

Franzisket, L. (1973). Uptake and accumulation of nitrate and nitrite by reef corals. Naturwissenschaften 60:552. doi: 10.1007/bf01178344

Fujise, L., Yamashita, H., Suzuki, G., Sasaki, K., Liao, L. M., and Koike, K. (2014). Moderate thermal stress causes active and immediate expulsion of photosynthetically damaged zooxanthellae (Symbiodinium) from corals. PLoS One 9:e114321. doi: 10.1371/journal.pone.0114321

Furla, P., Allemand, D., Shick, J. M., Ferrier-Pagès, C., Richier, S., Plantivaux, A., et al. (2005). The symbiotic anthozoan: a physiological chimera between alga and animal. Integr. Comp. Biol. 45, 595-604. doi: 10.1093/icb/45.4.595

Ghoshal, A., Eck, E., Gordon, M., and Morse, D. E. (2016). Wavelength-specific forward scattering of light by Bragg-reflective iridocytes in giant clams. J. $R$. Soc. Interface 13:20160285. doi: 10.1098/rsif.2016.0285

Glynn, P. W., and D'Croz, L. (1990). Experimental evidence for high temperature stress as the cause of El Nino-coincident coral mortality. Coral Reefs 8, 181-191. doi: 10.1007/BF00265009

Godinot, C., Ferrier-Pages, C., and Grover, R. (2009). Control of phosphate uptake by zooxanthellae and host cells in the scleractinian coral Stylophora pistillata. Limnol. Oceanogr. 54, 1627-1633. doi: 10.4319/lo.2009.54.5.1627

Godinot, C., Grover, R., Allemand, D., and Ferrier-Pages, C. (2011). High phosphate uptake requirements of the scleractinian coral Stylophora pistillata. J. Exp. Biol. 214, 2749-2754. doi: 10.1242/jeb.054239

Goh, G. H. S., and Todd, P. A. (2010). The distribution and status of giant clams (family Tridacnidae)-a short review. Raffles Bull. Zool. 58, 103-111.

Goiran, C., Al-Moghrabi, S., Allemand, D., and Jaubert, J. (1996). Inorganic carbon uptake for photosynthesis by the symbiotic coral/dinoflagellate association I. Photosynthetic performances of symbionts and dependence on sea water bicarbonate. J. Exp. Mar. Biol. Ecol. 199, 207-225. doi: 10.1016/0022-0981(95) 00201-4

Goreau, T. F. (1959). The physiology of skeleton formation in corals. I. A method for measuring the rate of calcium deposition by corals under different conditions. Biol. Bull. 116, 59-75. doi: 10.2307/1539156

Griffiths, C. L., and Klumpp, D. W. (1996). Relationships between size, mantle area and zooxanthellae numbers in five species of giant clam (Tridacnidae). Mar. Ecol. Prog. Ser. 137, 139-147. doi: 10.3354/meps137139

Griffiths, D. J., Winsor, H., and Luongvan, T. (1992). Iridophores in the mantle of giant clams. Aust. J. Zool. 40, 319-326. doi: 10.1071/zo9920319

Grover, R., and Maguer, J.-F. (2003). Nitrate uptake in the scleractinian coral Stylophora pistillata. Limnol. Oceanogr. 48, 2266-2274. doi: 10.4319/lo.2003. 48.6.2266

Grover, R., Maguer, J.-F., Allemand, D., and Ferrier-Pagès, C. (2006). Urea uptake by the scleractinian coral Stylophora pistillata. J. Exp. Mar. Biol. Ecol. 332, 216-225. doi: 10.1016/j.jembe.2005.11.020

Hastie, L. C., Heslinga, G. A., and Watson, T. C. (1988). "Lab test result: fertilizer speeds clam growth," in Micronesian Mariculture Demonstration Center Bulletin, Vol. 3, (Palau: Micronesian Mariculture Demonstration Centre).

Hastie, L. C., Watson, T. C., Isamu, T., and Heslinga, G. A. (1992). Effect of nutrient enrichment on Tridacna derasa seed: dissolved inorganic nitrogen increases growth rate. Aquaculture 106, 41-49. doi: 10.1016/0044-8486(92)90 248-j

Hawkins, A. J. S., and Klumpp, D. W. (1995). Nutrition of the giant clam Tridacna gigas (L.). II. Relative contributions of filter-feeding and the ammoniumnitrogen acquired and recycled by symbiotic alga towards total nitrogen requirements for tissue growth and metabolism. J. Exp. Mar. Biol. Ecol. 190, 263-290. doi: 10.1016/0022-0981(95)00044-r
Hermes-Lima, M. (2004). "Oxygen in biology and biochemistry: role of free radicals," in Functional Metabolism: Regulation, and Adaptation, ed. K. B. Storey (Hoboken, NJ: John Wiley \& Sons Inc), 319-368. doi: 10.1002/047167558x.ch12

Hernawan, U. E. (2008). Review: symbiosis between the giant clams (Bivalvia: Cardiidae) and zooxanthellae (Dinophyceae). Biodiversitas 9, 53-58. doi: 10. 13057/biodiv/d090113

Hiong, K. C., Choo, C. Y. L., Boo, M. V., Ching, B., Wong, W. P., Chew, S. F., et al. (2017b). A light-dependent ammonia-assimilating mechanism in the ctenidia of a giant clam. Coral Reefs 36, 311-323. doi: 10.1007/s00338-016-1502-4

Hiong, K. C., Cao-Pham, A. H., Choo, C. Y. L., Boo, M. V., Wong, W. P., Chew, S. F., et al. (2017a). Light-dependent expression of a $\mathrm{Na}^{+} / \mathrm{H}^{+}$exchanger 3like transporter in the ctenidium of the giant clam, Tridacna squamosa, can be related to increased $\mathrm{H}^{+}$excretion during light-enhanced calcification. Physiol. Rep. 5:e13209. doi: 10.14814/phy2.13209

Hiong, K. C., Koh, C. Z. Y., Boo, M. V., Choo, C. Y. L., Wong, W. P., Chew, S. F., et al. (2018). The colorful mantle of the giant clam, Tridacna squamosa, expresses a light-dependent manganese superoxide dismutase to ameliorate oxidative stresses due to its symbiotic association with zooxanthellae. Coral Reefs 37, 1039-1051. doi: 10.1007/s00338-018-01738-9

Holt, A. L., Vahidinia, S., Gagnon, Y. L., Morse, D. E., and Sweeney, A. M. (2014). Photosymbiotic giant clams are transformers of solar flux. J. R. Soc. Interface 11:20140678. doi: 10.1098/rsif.2014.0678

Houlbréque, F., and Ferrier-Pagés, C. (2009). Heterotrophy in tropical scleractinian corals. Biol. Rev. 84, 1-17. doi: 10.1111/j.1469-185x.2008.00058.x

Houlbrèque, F., Tambutte, E., Allemand, D., and Ferrier-Pagè, S. C. (2004). Interactions between zooplankton feeding, photosynthesis and skeletal growth in the scleractinian coral Stylophora pistillata. J. Exp. Biol. 207, 1461-1469. doi: 10.1242/jeb.00911

Houlbrèque, F., Tambutte, E., and Ferrier-Pagè, S. C. (2003). Effects of zooplankton availability on the rates of photosynthesis, and tissue and skeletal growth in the scleractinian coral Stylophora pistillata. J. Exp. Mar. Biol. Ecol. 296, 145-166. doi: 10.1016/s0022-0981(03)00259-4

Iglesias-Prieto, R., Bletran, V. H., LaJeunesse, T. C., Reyes-Bonilla, H., and Thome, P. E. (2004). Different algal symbionts explain the vertical distribution of dominant reef corals in the eastern Pacific. Proc. R. Soc. B 271, 1757-1763. doi: 10.1098/rspb.2004.2757

Ikeda, S., Yamashita, H., Kondo, S. N., Inoue, K., Morishima, S. Y., and Koike, K. (2017). Zooxanthellal genetic varieties in giant clams are partially determined by species-intrinsic and growth-related characteristics. PLoS One 12:e0172285. doi: 10.1371/journal.pone.0172285

Ip, Y. K., and Chew, S. F. (2010). Ammonia production, excretion, toxicity, and defence in fish: a review. Front. Physiol. 1:134. doi: 10.3389/fphys.2010.00134

Ip, Y. K., Ching, B., Hiong, K. C., Choo, C. Y. L., Boo, M. V., Wong, W. P., et al. (2015). Light induces changes in activities of $\mathrm{Na}^{+} / \mathrm{K}^{+}$-ATPase, $\mathrm{H}^{+} / \mathrm{K}^{+}$-ATPase and glutamine synthetase in tissues involved directly or indirectly in lightenhanced calcification in the giant clam, Tridacna squamosa. Front. Physiol. 6:68. doi: 10.3389/fphys.2015.00068

Ip, Y. K., Hiong, K. C., Goh, E. J. K., Boo, M. V., Choo, C. Y. L., Ching, B., et al. (2017a). The whitish inner mantle of the giant clam, Tridacna squamosa, expresses an apical Plasma Membrane $\mathrm{Ca}^{2+}$-ATPase (PMCA) which displays light-dependent gene and protein expressions. Front. Physiol. 8:781. doi: 10. 3389/fphys.2017.00781

Ip, Y. K., Koh, C. Z. Y., Hiong, K. C., Choo, C. Y. L., Boo, M. V., Wong, W. P., et al. (2017b). Carbonic anhydrase 2-like in the giant clam, Tridacna squamosa: characterization, localization, response to light, and possible role in the transport of inorganic carbon from the host to its symbionts. Physiol. Rep. 5:e13494. doi: 10.14814/phy2.13494

Ip, Y. K., Hiong, K. C., Lim, L. J. Y., Choo, C. Y. L., Boo, M. V., Wong, W. P., et al. (2018). Molecular characterization, light-dependent expression, and cellular localization of a host vacuolar-type $\mathrm{H}^{+}$-ATPase (VHA) subunit A in the giant clam, Tridacna squamosa, indicate the involvement of the host VHA in the uptake of inorganic carbon and its supply to the symbiotic zooxanthellae. Gene 659, 137-148. doi: 10.1016/j.gene.2018.03.054

Ip, Y. K., Hiong, K. C., Teng, J. H. Q., Boo, M. V., Choo, C. Y. L., Wong, W. P., et al. (2020a). The fluted giant clam (Tridacna squamosa) increases nitrate absorption and upregulates the expression of a homolog of SIALIN $\left(\mathrm{H}^{+}: 2 \mathrm{NO}_{3}{ }^{-}\right.$ cotransporter) in the ctenidium during light exposure. Coral Reefs 39, 451-465. doi: 10.1007/s00338-020-01907-9 
Ip, Y. K., Teng, G. C. Y., Boo, M. V., Poo, J. S. T., Hiong, K. C., Kim, H., et al. (2020b). Symbiodiniaceae dinoflagellates express urease in three subcellular compartments and upregulate its expression levels in situ in three organs of a giant clam (Tridacna squamosa) during illumination. J. Phycol. 56, 1696-1711. doi: 10.1111/jpy.13053

Ip, Y. K., Loong, A. M., Hiong, K. C., Wong, W. P., Chew, S. F., Reddy, K., et al. (2006). Light induces an increase in the $\mathrm{pH}$ of, and a decrease in the ammonia concentration in, the extrapallial fluid of the giant clam Tridacna squamosa. Physiol. Biochem. Zool. 79, 656-664. doi: 10.1086/501061

Jackson, A. E., Miller, D. J., and Yellowlees, D. (1989). Phosphorus metabolism in the coral-zooxanthellae symbiosis: characterization and possible roles of two acid phosphatases in the algal symbiont Symbiodinium sp. Proc. R. Soc. Lond. $B$ 238, 193-202. doi: 10.1098/rspb.1989.0076

Jackson, A. E., and Yellowlees, D. (1990). Phosphate uptake by zooxanthellae isolated from corals. Proc. R. Soc. Lond. B 242, 204-210.

Jantzen, C., Wild, C., El-Zibdah, M., Roa-Quiaoit, H. A., Haacke, C., and Richteret, C. (2008). Photosynthetic performance of giant clams, Tridacna maxima and T. squamosa, Red Sea. Mar. Biol. 155, 211-221. doi: 10.1007/s00227-0081019-7

Juinio, M. A. R., Menez, L. A. B., Villanoy, C. L., and Gomez, E. D. (1989). Status of giant clam resources of the Philippines. J. Molluscan Stud. 55, 431-440. doi: 10.1093/mollus/55.4.431

Klumpp, D. W., Bayne, B. L., and Hawkins, A. J. S. (1992). Nutrition of the giant clam Tridacna gigas (L.) I. Contribution of filter feeding and photosynthates to respiration and growth. J. Exp. Mar. Biol. Ecol. 155, 105-122. doi: 10.1016/ 0022-0981(92)90030-e

Klumpp, D. W., and Griffiths, C. L. (1994). Contributions of phototrophic and heterotrophic nutrition to the metabolic and growth requirements of four species of giant clam (Tridacnidae). Mar. Ecol. Prog. Ser. 115, 103-115. doi: 10.3354/meps 115103

Klumpp, D. W., and Lucas, J. S. (1994). Nutritional ecology of the giant clams Tridacna tevoroa and $T$. derasa from Tonga: influence of light on filterfeeding and photosynthesis. Mar. Ecol. Prog. Ser. 107, 147-156. doi: 10.3354/ meps 107147

Knowles, J. R. (1980). Enzyme-catalyzed phosphoryl transfer reactions. Ann. Rev. Biochem. 49, 877-919. doi: 10.1146/annurev.bi.49.070180.004305

Koh, C. Z. Y., Hiong, K. C., Choo, C. Y. L., Boo, M. V., Wong, W. P., Chew, S. F., et al. (2018). Molecular characterization of a dual domain carbonic anhydrase from the ctenidium of the giant clam, Tridacna squamosa, and its expression levels after light exposure, cellular localization, and possible role in the uptake of exogenous inorganic carbon. Front. Physiol. 9:281. doi: 10.3389/fphys.2018. 00281

LaJeunesse, T. C., Parkinson, J. E., Gabrielson, P. W., Jeong, H. J., Reimer, J. D., Voolstra, C. R., et al. (2018). Systematic revision of Symbiodiniaceae highlights the antiquity and diversity of coral endosymbionts. Curr. Biol. 28, 2570-2580. doi: 10.1016/j.cub.2018.07.008

Leggat, W., Badger, M. R., and Yellowlees, D. (1999). Evidence for an inorganic carbon concentrating mechanism in the symbiotic dinoflagellate Symbiodinium sp. Plant Physiol. 121, 1247-1255. doi: 10.1104/pp.121.4.1247

Leggat, W., Marendy, E. M., Baillie, B., Whitney, S. M., Ludwig, M., Badger, M. R., et al. (2002). Dinoflagellate symbioses: strategies and adaptations for the acquisition and fixation of inorganic carbon. Funct. Plant Biol. 29, 309-322. doi: $10.1071 / \mathrm{pp} 01202$

Lesser, M. P., Stochaj, W. R., Tapley, D. W., and Shick, J. M. (1990). Bleaching in coral-reef Anthozoans-effects of irradiance, ultraviolet-radiation, and temperature on the activities of protective enzymes against active oxygen. Coral Reefs 8, 225-232. doi: 10.1007/BF00265015

Leuchtenberger, W., Huthmacher, K., and Drauz, K. (2005). Biotechnological production of amino acids and derivatives: current status and prospects. Appl. Microbiol. Biotechnol. 69, 1-8. doi: 10.1007/s00253-005-0155-y

Levin, R. A., Beltran, V. H., Hill, R., Kjelleberg, S., McDougald, D., Steinberg, P. D., et al. (2016). Sex, scavengers, and chaperones: transcriptome secrets of divergent Symbiodinium thermal tolerances. Mol. Biol. Evol. 33:3032. doi: 10.1093/molbev/msw201

Liew, Y. J., Aranda, M., and Voolstra, C. R. (2016). Reefgenomics.Org-a repository for marine genomics data. Database 2016:baw152. doi: 10.1093/ database/baw152
Lim, S. S. Q., Huang, D., Soong, K., and Neo, M. L. (2019). Diversity of endosymbiotic Symbiodiniaceae in giant clams at Dongsha Atoll, northern South China Sea. Symbiosis 78, 251-262. doi: 10.1007/s13199-019-00615-5

Lucas, J. S., Nash, W. J., Crawford, C. M., and Braley, R. D. (1989). Environmental influences on growth and survival during the ocean-nursery rearing of giant clams, Tridacna gigas (L.). Aquaculture 80, 45-61. doi: 10.1016/0044-8486(89) 90272-x

Marshall, A. T. (1996). Calcification in hermatypic and ahermatypic corals. Science 271, 637-639. doi: 10.1126/science.271.5249.637

Mass, T., Giuffre, A. J., Sun, C. Y., Stifler, C. A., Frazier, M. J., Neder, M., et al. (2017). Amorphous calcium carbonate particles form coral skeletons. Proc. Natl. Acad. Sci. U.S.A. 114, E7670-E7678.

Mayfield, A. B., Hsiao, Y. Y., Chen, H. K., and Chen, C. S. (2014). Rubisco expression in the dinoflagellate Symbiodinium sp. is influenced by both photoperiod and endosymbiotic lifestyle. Mar. Biotechnol. 16, 371-384. doi: 10.1007/s10126-014-9558-z

Miller, D. J., and Yellowlees, D. (1989). Inorganic nitrogen uptake by symbiotic marine cnidarians: a critical review. Proc. R. Soc. B 237, 109-125. doi: 10.1098/ rspb.1989.0040

Mindell, J. A. (2012). Lysosomal acidification mechanisms. Annu. Rev. Physiol. 74, 69-86. doi: 10.1146/annurev-physiol-012110-142317

Mingoa, S. M. (1988). "Photoadaptation in juvenile Tridacna gigas," in Giant Clams in Asia and the Pacific, ACIAR Monograph No. 9, eds J. W. Copland and J. S. Lucas (Canberra: Australian Centre for International Agricultural Research), $145-150$.

Morishima, S.-Y., Yamashita, H., O-hara, S., Nakamura, Y., Quek, V. Z. Q., Yamauchi, M., et al. (2019). Study on expelled but viable zooxanthellae from giant clams, with an emphasis on their potential as subsequent symbiont sources. PLoS One 14:e220141. doi: 10.1371/journal.pone.0220141

Morse, D., Salois, P., Markovic, P., and Hastings, J. W. (1995). A nuclear-encoded form II RuBisCO in dinoflagellates. Science 268, 1622-1624. doi: 10.1126/ science.7777861

Muscatine, L. (1990). "The role of symbiotic algae in carbon and energy flux in reef corals," in Ecosystems of the World, Vol. 25, ed. Z. Dubinsky (Amsterdam: Elsevier), 75-87.

Muscatine, L., and D'Elia, C. E. (1978). The uptake, retention and release of ammonium by reef corals. Limnol. Oceanogr. 23, 725-734. doi: 10.4319/lo.1978. 23.4.0725

Neo, M. L., Eckman, W., Vicentuan, K., Teo, S. L.-M., and Todd, P. A. (2015). The ecological significance of giant clams in coral reef ecosystems. Biol. Conserv. 181, 111-123. doi: 10.1016/j.biocon.2014.11.004

Neo, M. L., Wabnitz, C. C. C., Braley, R. D., Heslinga, G. A., Fauvelot, C., Wynsberge, S. V., et al. (2017). Giant clams (Bivalvia: Cardiidae: Tridacninae): a comprehensive update of species and their distribution, current threats and conservation status. Oceanogr. Mar. Biol. 55, 87-387. doi: 10.1201/b21944-5

Norton, J. H., and Jones, G. W. (1992). The giant Clam: An Anatomical and Histological Atlas. Canberra, ACT: Australian Centre for International Agricultural Research.

Norton, J. H., Shepherd, M. A., Long, H. M., and Fitt, W. K. (1992). The zooxanthellal tubular system in the giant clam. Biol. Bull. 183, 503-506. doi: $10.2307 / 1542028$

Olsen, J. V., Blagoev, B., Gnad, F., Macek, B., Kumar, C., Mortensen, P., et al. (2006). Global, in vivo, and site-specific phosphorylation dynamics in signaling networks. Cell 127, 635-648. doi: 10.1016/j.cell.2006.09.026

Onate, J. A., and Naguit, M. R. A. (1989). "A preliminary study on the effect of increased nitrate concentration on the growth of giant clams Hippopus hippopus," in Culture of Giant Clams (Bivalvia: Tridacnidae), eds E. C. Zaragoza, D. L. de Guzman, and E. P. Gonzales (Canberra, ACT: Australian Centre for International Agricultural Research), 57-61.

Pochon, X., Wecker, P., Stat, M., Berteaux-Lecellier, V., and Lecellier, G. (2019). Towards an indepth characterization of Symbiodiniaceae in tropical giant clams via metabarcoding of pooled multi-gene amplicons. PeerJ 7:e6898. doi: 10.7717/ peerj.6898

Poo, J. S. T., Boo, M. V., Chew, S. F., and Ip, Y. K. (2021). Using form II ribulose-1,5-bisphosphate carboxylase/oxygenase to estimate the phototrophic potentials of Symbiodinium, Cladocopium and Durusdinium in various organs of the fluted giant clam, Tridacna squamosa, and to evaluate their responses 
to light upon isolation from the host. Coral Reefs doi: 10.1007/s00338-02002031-4 [Epub ahead of print].

Poo, J. S. T., Choo, C. Y. L., Hiong, K. C., Boo, M. V., Wong, W. P., Chew, S. F., et al. (2020). Phototrophic potential and form II ribulose-1,5-bisphosphate carboxylase/oxygenase expression in five organs of the fluted giant clam, Tridacna squamosa. Coral Reefs 39, 361-374. doi: 10.1007/s00338-020-01 898-7

Perry, J. J. P., Shin, D. S., Getzoff, E. D., and Tainer, J. A. (2010). The structural biochemistry of the superoxide dismutases. Biochim. Biophys. Acta Proteins Proteom. 1804, 245-262. doi: 10.1016/j.bbapap.2009.11.004

Rees, T. A. (1991). Are symbiotic algae nutrient deficient? Proc. R. Soc. Lond. B Biol. 243, 227-233. doi: 10.1098/rspb.1991.0036

Rees, T. A., Fitt, W. K., and Yellowlees, D. (1994). Host glutamine synthetase activities in the giant clam-zooxanthellae symbiosis: effects of clam size, elevated ammonia and continuous darkness. Mar. Biol. 118, 681-685. doi: 10.1007/ bf00347516

Rees, T. A. V., Fitt, W. K., and Yellowlees, D. (1993). "The haemolymph and its temporal relationship with zooxanthellae metabolism in the giant clam symbiosis," in Biology and Mariculture of Giant Clams, ed. W. K. Fitt (Canberra, ACT: Pirie Printers), 41-45.

Rivkin, R. B., and Swift, E. (1985). Phosphorus metabolism of oceanic dinoflagellates: phosphate uptake, chemical composition and growth of Pyrocystis noctiluca. Mar. Biol. 88, 189-198. doi: 10.1007/bf00397166

Rosic, N., Yew, E. S. L., Chan, C. K. K., Lee, H. C., Kaniewska, P., Edwards, D., et al. (2015). Unfolding the secrets of coral-algal symbiosis. ISME J. 9, 844-856. doi: 10.1038 /ismej.2014.182

Rossbach, S., Cardenas, A., Perna, G., Duarte, C. M., and Voolstra, C. R. (2019a), Tissue-specific microbiomes of the Red Sea giant clam Tridacna maxima highlight differential abundance of Endozoicomonadaceae. Front. Microbiol. 10:2661. doi: 10.3389/fmicb.2019.02661

Rossbach, S., Saderne, V., Anton, A., and Durarte, C. M. (2019b). Light-dependent calcification in Red Sea giant clam Tridacna maxima. Biogeosciences 16, 2635 2650. doi: $10.5194 /$ bg-16-2635-2019

Rossbach, S., Subedi, R. C., Ng, T. K., Ooi, B. S., and Durarte, C. M. (2020). Iridocytes mediate photonic cooperation between giant clams (Tridacninae) and their photosynthetic symbionts. Front. Mar. Sci. 7:465. doi: 10.3389/fmars. 2020.00465

Rosset, S., Wiedenmann, J., Reed, A. J., and D’Angelo, C. (2017). Phosphate deficiency promotes coral bleaching and is reflected by the ultrastructure of symbiotic dinoflagellates. Mar. Pollut. Bull. 118, 180-187. doi: 10.1016/j. marpolbul.2017.02.044

Rowan, R., Whitney, S. M., Fowler, A., and Yellowlees, D. (1996). Rubisco in marine symbiotic dinoflagellates: form II enzymes in eukaryotic oxygenic phototrophs encoded by a nuclear multigene family. Plant Cell 8, 539-553. doi: 10.1105/tpc. 8.3.539

Salvador, J. M., Inesi, G., Rigaud, J. L., and Mata, A. M. (1998). Ca ${ }^{2+}$ transport by reconstituted synaptosomal ATPase is associated with $\mathrm{H}^{+}$countertransport and net charge displacement. J. Biol. Chem. 273, 18230-18234. doi: 10.1074/jbc.273. 29.18230

Sano, Y., Kobayashi, S., Shirai, K., Takahata, N., Matsumoto, K., Watanabe, T., et al. (2012). Past daily light cycle recorded in the strontium/calcium ratios of giant clam shells. Nat. Commun. 3:761. doi: 10.1038/ncomms1763

Scandalios, J. G. (2005). Oxidative stress: molecular perception and transduction of signals triggering antioxidant gene defenses. Braz. J. Med. Biol. Res. 38, 995-1014. doi: 10.1590/S0100-879X2005000700003

Shah, G. N., Ulmasov, B., Waheed, A., Becker, T., Makani, S., Svichar, N., et al. (2005). Carbonic anhydrase IV and XIV knockout mice: roles of the respective carbonic anhydrases in buffering the extracellular space in brain. Proc. Natl. Acad. Sci. U.S.A. 102, 16771-16776. doi: 10.1073/pnas.050844 9102

Shepherd, D., Leggat, W., Rees, T. A. V., and Yellowlees, D. (1999). Ammonium, but not nitrate, stimulates an increase in glutamine concentration in the haemolymph of Tridacna gigas. Mar. Biol. 133, 45-53. doi: 10.1007/ s002270050441

Shoguchi, E., Beedessee, G., Tada, I., Hisata, K., Takeshi, K., Takeshi, T., et al. (2018). Two divergent Symbiodinium genomes reveal conservation of a gene cluster for sunscreen biosynthesis and recently lost genes. BMC Genomics 19:458. doi: 10.1186/s12864-018-4857-9
Stock, D., Gibbons, C., Arechaga, I., Leslie, A. G. W., and Walker, J. E. (2000). The rotary mechanism of ATP synthase. Curr. Opin. Struct. Biol. 10, 672-679. doi: $10.1016 / \mathrm{s} 0959-440 x(00) 00147-0$

Streamer, M., McNeil, Y. R., and Yellowless, D. (1993). Photosynthetic carbon dioxide fixation in zooxanthellae. Mar. Biol. 115, 195-198. doi: 10.1007/ bf00346335

Sturtz, L. A., Diekert, K., Jensen, L. T., Lill, R., and Culotta, V. C. (2001). A fraction of yeast $\mathrm{Cu}, \mathrm{Zn}$-superoxide dismutase and its metallochaperone, CCS, localize to the intermembrane space of mitochondria: a physiological role for SOD1 in guarding against mitochondrial oxidative damage. J. Biol. Chem. 276, 38084-38089. doi: 10.1074/jbc.M105296200

Summons, R. E., Boag, T. S., and Osmond, C. B. (1986). The effect of ammonium on photosynthesis and the pathway of ammonium assimilation in Gymnodinium microadriaticum in vitro and in symbiosis with tridacnid clams and corals. Proc. R. Soc. Lond. B Biol. 227, 147-159. doi: 10.1098/rspb.1986.0016

Supuran, C. T. (2008). Carbonic anhydrases: novel therapeutic applications for inhibitors and activators. Nat. Rev. Drug Discov. 7, 168-181. doi: 10.1038/ $\operatorname{nrd} 2467$

Swanson, R., and Hoegh-Guldberg, O. (1998). Amino acid synthesis in the symbiotic sea anemone Aiptasia pulchella. Mar. Biol. 131, 83-93. doi: 10.1007/ s002270050299

Swarts, H. G., Koenderink, J. B., Willems, P. H., and De Pont, J. J. (2005). The non-gastric $\mathrm{H}, \mathrm{K}$-ATPase is oligomycin-sensitive and can function as an $\mathrm{H}^{+}$, $\mathrm{NH}^{4+}$-ATPase. J. Biol. Chem. 280, 33115-33122. doi: 10.1074/jbc.m504535200 Szmant, A. M., and Gassman, N. J. (1990). The effects of prolonged "bleaching" on the tissue biomass and reproduction of the reef coral Montastrea annularis. Coral Reefs 8, 217-224. doi: 10.1007/bf00265014

Tambuttè, E., Allemand, D., Mueller, E., and Jaubert, J. (1996). A compartmental approach to the mechanism of calcification in hermatypic corals. J. Exp. Biol. 199, 1029-1041.

Taylor, L., and Curthoys, N. P. (2004). Glutamine metabolism: role in acidbase balance. Biochem. Mol. Biol. Educ. 32, 291-304. doi: 10.1002/bmb.2004 494032050388

Trench, R. K., Wethey, D. S., and Porter, J. W. (1981). Observations on the symbiosis with zooxanthellae among the Tridacnidae (Mollusca, Bivalvia). Biol. Bull. 161, 180-198. doi: 10.2307/1541117

Tresguerres, M. (2016). Novel and potential physiological roles of vacuolar-type $\mathrm{H}^{+}$-ATPase in marine organisms. J. Exp. Biol. 219, 2088-2097. doi: 10.1242/jeb. 128389

Umeki, M., Yamashita, H., Suzuki, G., Sato, T., Ohara, S., and Koike, K. (2020). Fecal pellets of giant clams as a route for transporting Symbiodiniaceae to corals. PLoS One 15:e243087. doi: 10.1371/journal.pone.0243087

Van Wynsberge, S., Andréfouët, S., Gaertner-Mazouni, N., Wabnitz, C. C., Gilbert, A., Remoissenet, G., et al. (2016). Drivers of density for the exploited giant clam Tridacna maxima: a meta-analysis. Fish Fish. 17, 567-584. doi: 10.1111/ faf. 12127

Von Euw, S., Zhang, Q., Manichev, V., Murali, N., Gross, J., Feldman, L. C., et al. (2017). Biological control of aragonite formation in stony corals. Science 356, 933-938. doi: 10.1126/science.aam6371

Watanabe, T., and Oba, T. (1999). Daily reconstruction of water temperature from oxygen isotopic ratios of a modern Tridacna shell using a freezing microtome sampling technique. J. Geophys. Res. 104, 667-674.

Watson, S. A. (2015). Giant clams and rising $\mathrm{CO}_{2}$ : light may ameliorate effects of ocean acidification on a solar-powered animal. PLoS One 10:e0128405. doi: 10.137/journal.pone. 0128405

Watson, S. A., Southgate, P. C., Miller, G. M., Moorhead, J. A., and Knauer, J. (2012). Ocean acidification and warming reduce juvenile survival of the flutted giant clam Tridacna squamosa. Molluscan Res. 32, 177-180.

Wheeler, A. P., and Sikes, C. S. (1984). Regulation of carbonate calcification by organic matrix. Am. Zool. 24, 933-944. doi: 10.1093/icb/24.4.933

Wilbur, K. M., and Saleuddin, A. S. M. (1983). "Shell formation," in The Mollusca, eds A. S. M. Saleuddin and K. M. Wilbut (Massachusetts, MA: Academic Press), 235-287.

Wilbur, K. M., and Watabe, N. (1963). Experimental studies on calci?cation in molluscs and the alga Coccolithus huxleyi. Ann. N. Y. Acad. Sci. 109, 82-112. doi: 10.1111/j.1749-6632.1963.tb13463.x 
Wilkerson, F. P., and Muscatine, L. (1984). Uptake and assimilation of dissolved inorganic nitrogen by a symbiotic sea anemone. Proc. R. Soc. Lond. B Biol. 221, 71-86. doi: $10.1098 / \mathrm{rspb} .1984 .0023$

Wilkerson, F. P., and Trench, R. K. (1986). Uptake of dissolved inorganic nitrogen by the symbiotic clam Tridacna gigas and the coral Acropora sp. Mar. Biol. 93, 237-246. doi: 10.1007/bf00508261

Xiang, T., Lehnert, E., Jinkerson, R. E., Clowez, S., Kim, R. G., DeNofrio, J. C., et al. (2020). Symbiont population control by host-symbiont metabolic interaction in Symbiodiniaceae-cnidarian associations. Nat. Comm. 11:108. doi: 10.1038/ s41467-019-13963-z

Yellowlees, D., Dionisio-Sese, M. L., Masuda, K., Maruyama, T., Abe, T., Baillie, B., et al. (1993). Role of carbonic anhydrase in the supply of inorganic carbon to the giant clam-zooxanthellate symbiosis. Mar. Biol. 115, 605-611. doi: 10.1007/ bf00349368

Yellowlees, D., Rees, T. A. V., and Fitt, W. K. (1994). Effect of ammoniumsupplemented seawater on glutamine synthetase and glutamate dehydrogenase activities in host tissue and zooxanthellae of Pocillopora damicornis and on ammonium uptake rates of the zooxanthellae. Pac. Sci. 48, 291-295.

Zoccola, D., Tambutteì, E., Seìneìgas-Balas, F., Michiels, J. F., Failla, J. P., Jaubert, J., et al. (1999). Cloning of a calcium channel $\alpha 1$ subunit from the reef-building coral Stylophora pistillata. Gene 227, 157-167. doi: 10.1016/s0378-1119(98) 00602-7

Conflict of Interest: The authors declare that the research was conducted in the absence of any commercial or financial relationships that could be construed as a potential conflict of interest.

Copyright (c) 2021 Ip and Chew. This is an open-access article distributed under the terms of the Creative Commons Attribution License (CC BY). The use, distribution or reproduction in other forums is permitted, provided the original author(s) and the copyright owner(s) are credited and that the original publication in this journal is cited, in accordance with accepted academic practice. No use, distribution or reproduction is permitted which does not comply with these terms. 